\title{
Chapter 1. Introduction of selenium and tellurium into reaction systems
}

Risto S. Laitinen, ${ }^{a}$ Raija Oilunkaniemi, ${ }^{a}$ and Tristram Chivers ${ }^{b}$

${ }^{a}$ Laboratory of Inorganic Chemistry, Environmental and Chemical Engineering, University of Oulu, P.O. Box 3000, 90014 Oulu, Finland. ${ }^{b}$ Department of Chemistry, University of Calgary, 2500 University Drive NW, Calgary, Alberta, Canada T2N 1N4

\section{Table of Contents}

1. Introduction

2. Elemental selenium

\subsection{General}

2.2 Anionic selenides and their derivatives

2.3 Selenium halogenides

2.4 Heterocyclic selenium sulfides

2.5 Homopolyatomic selenium cations

2.6 Triorganylphosphine selenides

2.7 Grignard and organyllithium reagents

2.8 Selenium and heavy group 14 reagents

2.9 Selenium-boron chemistry

2.10 Transition metal selenides

3. Elemental tellurium 
3.1 General

3.2 Anionic tellurides

3.3 Derivatives of anionic tellurides

3.4 Tellurium-containing chalcogen rings

3.5 Homopolyatomic tellurium cations

3.6 Triorganylphosphine tellurides

3.7 Grignard and organyllithium reagents

3.8 Silane- and germanetellones

3.9 Group 13 chemistry with tellurium

3.10 Titanocene chemistry

3.11 Solid-state and hydrothermal reactions

4. Summary

5. References 


\begin{abstract}
There are several commercial selenium and tellurium compounds that are useful in synthetic chemistry. The introduction of selenium and tellurium into both organic and inorganic compounds frequently begins with the elements. This chapter provides an overview of the main reactivity of the hexagonal allotropes of selenium and tellurium, which are the most stable form of the elements under ambient conditions. While the two elements have very similar chemical properties, there are also notable differences. Upon reduction, both elements form mono- and poly-chalcogenides, which are useful nucleophilic reagents in several reactions. The elements also react with many main group compounds as well as with transition metal complexes. They also form homopolyatomic cations upon oxidation. Both selenium and tellurium react with Grignard reagents and organyllithium compounds affording organylchalcogenolates, which upon oxidation form dichalcogenides that are themselves useful reagents in organic synthetic chemistry as well as in materials applications. This chapter provides a short introduction to the various topics that will be developed further in the subsequent chapters of this book.
\end{abstract}

Keywords: Elemental selenium, elemental tellurium, selenides, tellurides, polyselenides, polytellurides, organyl selenolates, organyl tellurolates, homopolyselenium cations, homopolytellurium cations 


\section{Introduction}

The use of selenium and tellurium compounds in diverse applications has grown significantly during the past decades. Consequently, chalcogen chemistry has been reviewed several times during the last twenty years, as exemplified by a selection of review articles [1-6] and books [7-16], which describe recent advances in synthetic inorganic and organic chalcogen chemistry, as well as in more applied areas such as medicinal chemistry and materials science. The current monograph is an overview of this progress and discusses the use of different classes of selenium and tellurium compounds as reagents.

The preparation of selenium and tellurium compounds generally involves simple molecular species such as the elements, inorganic or organic chalcogenides and polychalcogenides, selenium and tellurium halogenides, selenium and tellurium oxides, as well as organyl phosphine selenides and tellurides. These classes are treated in detail in the subsequent chapters of this monograph. In this chapter, the introduction of commercially available selenium and tellurium into the reaction system is considered. The first step in many reactions of selenium and tellurium is the reduction of the elements to form anionic selenides and tellurides, which are the actual reagents.

Alkyl or aryl selenides, tellurides, diselenides, and ditellurides are also common starting materials in many organic syntheses. While many of them are commercially available, they can also be conveniently prepared from the elements. The dimer $\operatorname{PhPSe}(\mu-\mathrm{Se})_{2} \mathrm{P}(\mathrm{Ph}) \mathrm{Se}$, which is known as Woollins' reagent, is also commercially available. This $\mathrm{P}-\mathrm{Se}$ compound is proving to be an important 
source of selenium in a wide range of synthetic applications. Its chemistry is discussed in detail in Chapter 5.

\section{Elemental selenium}

\subsection{General}

Some reactions of elemental selenium are summarized in Figure 1. Many of the products are themselves useful reagents in further syntheses. Special examples have been discussed in the appropriate chapters of this monograph.

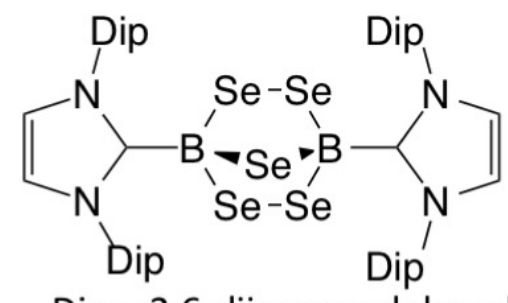
$\mathrm{Se}_{x}^{2-}$

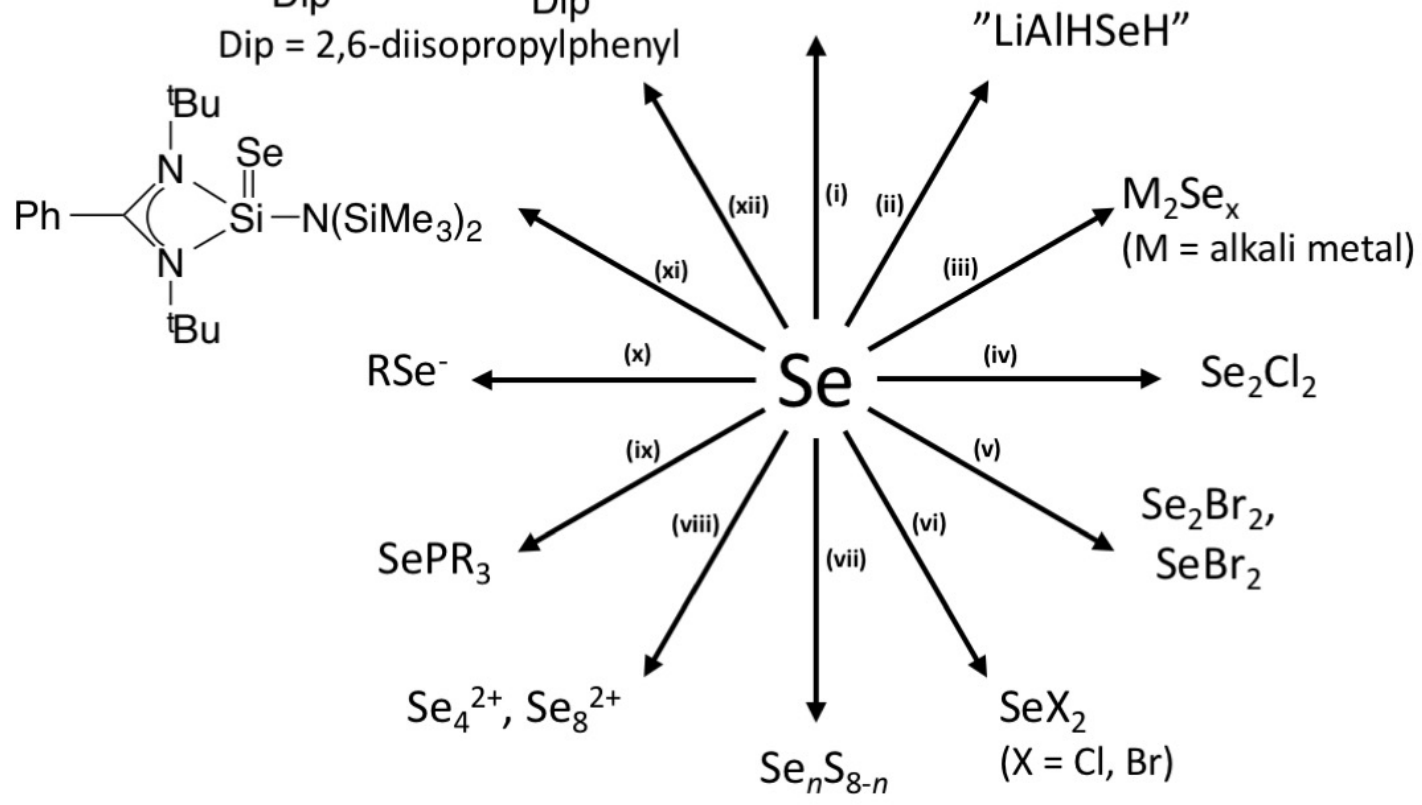

Figure 1. Some reactions of elemental selenium. (i) $\mathrm{M} / \mathrm{NH}_{3}(\mathrm{l})(\mathrm{M}=\mathrm{Li}, \mathrm{Na}, \mathrm{K}), \mathrm{Na}\left[\mathrm{BH}_{4}\right]$, or $\mathrm{Li}\left[\mathrm{AlEt}_{3} \mathrm{H}\right.$ ], (ii) $\mathrm{Li}\left[\mathrm{AlH}_{4}\right]$, (iii) $\mathrm{M}_{2} \mathrm{Se}\left(\mathrm{M}=\right.$ alkali metal), (iv) $\mathrm{SeCl}_{4}$, (v) $\mathrm{Br}_{2}$, (vi) $\mathrm{SO}_{2} \mathrm{X}_{2} / \mathrm{THF}$ (X = $\mathrm{Cl}, \mathrm{Br}$ ), (vii) $\mathrm{S}_{8}$, (viii) $\mathrm{AsF}_{5} / \mathrm{SO}_{2}$ (l) or $\mathrm{SbCl}_{5} / \mathrm{SO}_{2}$ (l), (ix) $\mathrm{PR}_{3}$ ( $\mathrm{R}=$ alkyl or aryl), (x) $\mathrm{RMgBr} / \mathrm{THF}$ or $\mathrm{RLi} / \mathrm{THF}\left(\mathrm{R}=\right.$ alkyl or aryl), (xi) $\mathrm{PhC}\left(\mathrm{N}^{\mathrm{t} B u}\right)_{2} \mathrm{Si}\left[\mathrm{N}\left(\mathrm{SiMe}_{3}\right)_{2}\right] / \mathrm{THF}$, (xii) $\left\{\left[\mathrm{N}(\mathrm{Dip})_{2}\right]_{2}(\mathrm{CH})_{2} \mathrm{CB}\right\}_{2} / \mathrm{C}_{6} \mathrm{H}_{6}$. 


\subsection{Anionic selenides and their derivatives}

Selenides and polyselenide anions are useful nucleophiles in synthetic applications. Alkali metal and alkaline earth metal chalcogenides are commonly prepared by mixing the elements at high temperatures, by the reaction of chalcogen elements and alkali-metal carbonates in solution, by solvothermal reactions, and by oxidation-reduction reactions involving Lewis acids $[17,18]$. The alkali metal or alkaline earth metal selenides and tellurides thus formed can serve as reagents for the preparation of transition-metal or main-group element chalcogenides. A large organic cation or an encapsulating agent such as the crown-ether complex of an alkali-metal cation may stabilize the otherwise unstable anions.

Lithium, sodium and potassium selenides and diselenides have traditionally been prepared by dissolving the chalcogen elements and the alkali metals in appropriate molar ratios in liquid ammonia. The early work by Bergström [19] and Klemm et al. [20], as well as that by Brandsma and Wijers [21] has been followed and developed by numerous studies, as exemplified by Müller et al. [22], Björgvinsson and Schrobilgen [23], and Colombara et al. [24]. Thiele et al. [25] have recently reviewed the preparation, structures, and properties of different classes of polyselenides, which have been stabilized by use of bulky cations.

In addition to alkali metals, polyselenides can be produced in liquid ammonia or in methylamine by other less-noble metals such as $\mathrm{Mn}$ and Fe to afford $\left[\mathrm{Mn}\left(\mathrm{NH}_{3}\right)_{6}\right] \mathrm{Se}_{3},\left[\mathrm{Mn}\left(\mathrm{NH}_{3}\right)_{6}\right] \mathrm{Se}_{4},\left[\mathrm{M}\left(\mathrm{NH}_{3}\right)_{6}\right] \mathrm{Se}_{6}$ $(\mathrm{M}=\mathrm{Mn}, \mathrm{Fe})$, and disordered phases $\left[\mathrm{Mn}\left(\mathrm{NH}_{2} \mathrm{Me}\right)_{6}\right]\left(\mathrm{S}_{5}\right)_{0.15}\left(\mathrm{Se}_{2.43} \mathrm{~S}_{1.57}\right)_{0.85}$ and $\left[\mathrm{Mn}\left(\mathrm{NH}_{3}\right)_{6}\right]\left(\mathrm{Se}_{2.29} \mathrm{~S}_{2.71}\right)[26]$.

Sandman et al. [27] have shown that alkali-metal selenides can also be produced upon reduction of selenium by elemental alkali metals in high-boiling polar aprotic solvents. This concept has been 
developed by Thompson and Boudjouk [28], who have demonstrated that lithium, sodium, and potassium selenides and diselenides can conveniently be also prepared in THF by use of ultrasound and in the presence of small amounts of a charge-transfer agent such as naphthalene. The electrochemical reduction of selenium powder in aprotic media such as acetonitrile or THF also provides an effective method to synthesize $\mathrm{Se}^{2-}$ and $\mathrm{Se}_{2}{ }^{2-}$ selectively $[29,30]$.

Elemental selenium can also conveniently be reduced by using lithium tetrahydridoaluminate [31], sodium tetrahydridoborate [32], or lithium triethylhydridoborate [33]. The reaction with lithium tetrahydridoaluminate ("lithium aluminium hydride") has been reported to produce an intermediate product "LiAlHSeH", which can be used in situ to produce a wide variety of organic selenoethers and selenones [31]. This reagent is described in more detail in Chapter 8 .

Since the distribution of the products in the reduction of elemental selenium with sodium tetrahydridoborate seemed to be sensitive to experimental conditions, Cusic and Dance [34] and Marques de Oliveira et al. [35] have studied the reaction in detail using ${ }^{77}$ Se NMR spectroscopy. Since $\mathrm{HSe}^{-}$and $\mathrm{Se}^{2-}$ co-exist in fast equilibrium, there is no NMR evidence for the presence of $\mathrm{Se}^{2-}$. Similarily, no resonance attributable to $\mathrm{Se}_{2}{ }^{2-}$ has been observed. By contrast, the presence of polyselenide anions $\mathrm{Se}_{x}{ }^{2-}(x=3-6)$ is clearly evident in solution, as indicated in Figure 2 by the ${ }^{77} \mathrm{Se}$ NMR spectrum of a reaction mixture recorded in DMF [34]. These observations are consistent with the detailed ${ }^{77} \mathrm{Se}$ NMR study of Björgvinsson and Schrobligen in liquid ammonia and ethylenediamine [23] and with the ESI mass spectrometric study of the polyselenide speciation by Raymond et al. [36]. 


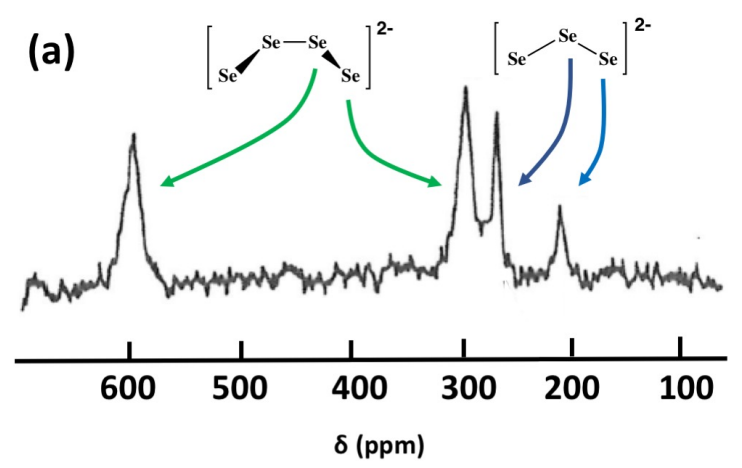

(b)

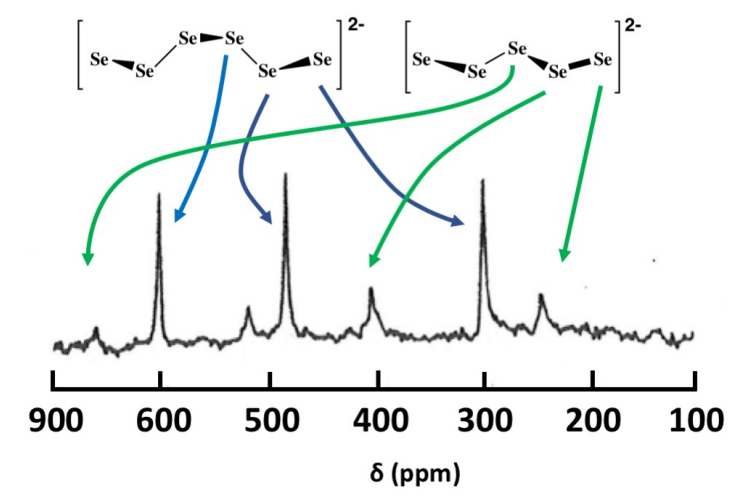

Figure 2. ${ }^{77} \mathrm{Se} \mathrm{NMR}$ resonances of (a) $\mathrm{Se}_{3}{ }^{2-}$ and $\mathrm{Se}_{4}{ }^{2-}$, and (b) $\mathrm{Se}_{5}{ }^{2-}$ and $\mathrm{Se}_{6}{ }^{2-}$. All spectra have been recorded in DMF [34] (adapted from Cusick J, Dance I. The characterization of [HSe] ${ }^{-}$and $\left[\mathrm{Se}_{x}\right]^{2-}$ ions by ${ }^{77}$ Se NMR. Polyhedron 1991, 10, 2629-2640. Copyright 1991 Elsevier SA).

Klayman and Griffin [32] and Marques de Oliveira et al. [35] have shown that the treatment of $\mathrm{Se}_{x}^{2-}$ solutions with organyl halogenides with careful control of the reaction stoichiometry produces organyl selenides and diselenides in high purity. The solvothermal synthesis of $\mathrm{CuInSe}_{2}$ also involves $\mathrm{Se}_{x}^{2-}$, which has been produced by the reduction of selenium with $\mathrm{NaBH}_{4}$ [37].

The reduction of selenium by lithium triethylhydridoborate ("superhydride") also results in the formation of a mixture of polyselenides $\mathrm{Se}_{\mathrm{x}}{ }^{2-}$ [33]. The distribution of polyselenide anions is dependent on the molar ratio of selenium and the reducing agent. The treatment of the anions with [TiCp $\left.{ }_{2} \mathrm{Cl}_{2}\right]$ affords $\left[\mathrm{TiCp}_{2} \mathrm{Se}_{5}\right][38-40]$ or dinuclear $\left[\mathrm{TiCp}_{2}\left(\mu-\mathrm{Se}_{2}\right)_{2} \mathrm{TiCp}_{2}\right][\mathrm{Cp}=$ cyclopentadienyl ligand $\mathrm{C}_{5} \mathrm{H}_{5}^{-}$, or its alkyl-substituted derivatives) [41]. 
Both $\left[\mathrm{TiCp}_{2} \mathrm{Se}_{5}\right]$ and $\left[\mathrm{TiCp}_{2}\left(\mu-\mathrm{Se}_{2}\right)_{2} \mathrm{TiCp}_{2}\right]$ are useful reagents for the preparation of homo- and heterocyclic chalcogen rings by the reaction with $\mathrm{Se}_{2} \mathrm{Cl}_{2}$ or $\mathrm{SeCl}_{2}[42,43]$ (see Eqs. 1 and 2). These reactions are similar to those of $\left[\mathrm{TiCp}_{2} \mathrm{~S}_{5}\right]$ and $\mathrm{S}_{n} \mathrm{Cl}_{2}$, which afford a large number of homocyclic sulfur ring molecules $\mathrm{S}_{n+5}$ (for reviews, see refs. [44-46]). The hybrid reactions of [TiCp $\left.\mathrm{S}_{5}\right]$ or $\left[\mathrm{TiCp}_{2}\left(\mu-\mathrm{S}_{2}\right)_{n} \mathrm{TiCp}_{2}\right](n=2,3)$ with $\mathrm{Se}_{2} \mathrm{Cl}_{2}[41]$ and those of $\left[\mathrm{TiCp}_{2} \mathrm{Se}_{5}\right]$ or $\left[\mathrm{TiCp}_{2}\left(\mu-\mathrm{Se}_{2}\right)_{2} \mathrm{TiCp}_{2}\right]$ with $\mathrm{S}_{n} \mathrm{Cl}_{2}(n=1,2)[41,47,48]$ afford heterocyclic selenium sulfides, as do the reactions of $\left[\mathrm{TiCp}_{2} \mathrm{Se}_{n} \mathrm{~S}_{5-}\right.$ n] mixtures with sulfur or selenium chlorides [48,49].

$$
\begin{aligned}
& {\left[\mathrm{TiCp}_{2} \mathrm{Se}_{5}\right]+\mathrm{Se}_{n} \mathrm{Cl}_{2} \rightarrow \quad \mathrm{Se}_{5+n}+\left[\mathrm{TiCp}_{2} \mathrm{Cl}_{2}\right]} \\
& {\left[\mathrm{TiCp}_{2}\left(\left(\mu-\mathrm{Se}_{2}\right)_{2} \mathrm{TiCp}_{2}\right]+2 \mathrm{Se}_{n} \mathrm{Cl}_{2} \rightarrow \quad \mathrm{Se}_{4+2 n}+2\left[\mathrm{TiCp}_{2} \mathrm{Cl}_{2}\right](n=1,2)\right.}
\end{aligned}
$$

An intriguing application of the reduction of elemental selenium by lithium triethylhydridoborate involves the reaction of the reduction product with acyl chlorides or carboxylic acids followed by treatment with sugar azides [50] (see Figure 3). A new amide bond is formed and elemental selenium is recovered for further use.

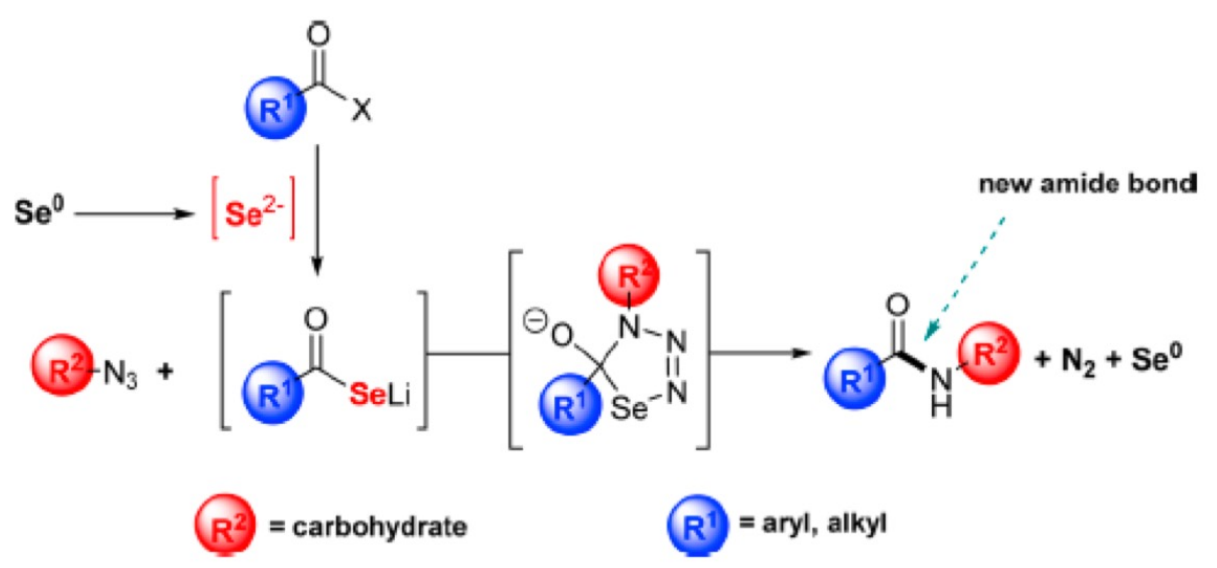

Figure 3. The preparation of sugar-derived amides by reduction of elemental selenium with lithium triethylhydridoaluminate followed by a reaction with an acyl chloride [50] (reproduced with permission from Silva L, Affeldt RF, Lüdtke DS. Synthesis of glycosyl amides using selenocarboxylates as traceless reagents for amide bond formation. J Org Chem 2016, 81, 5464-5473. Copyright 2016 Americal Chemical Society). 
Elemental selenium can also be reduced to $\mathrm{Se}^{2-}$ in aqueous alkaline solution [51], though it was reported that the yield of the $\mathrm{Se}^{2-}$ ion is only moderate owing to disproportionation (see eq. 3 ). When tin(II) chloride was added to the basic media, the yield was significantly improved. It has been deduced that tin(II) oxide was de facto the reducing agent. However, when selenium powder was irradiated in the microwave oven in a $\mathrm{NaOH}$ solution and subsequently treated with $\mathrm{CuSO}_{4} \cdot 5 \mathrm{H}_{2} \mathrm{O}$, bulk $\mathrm{Cu}_{5} \mathrm{Se}_{4}$ could be precipitated from the solution [52].

$$
3 \mathrm{X}+6 \mathrm{MOH} \quad \rightarrow \quad 2 \mathrm{M}_{2} \mathrm{X}+\mathrm{M}_{2} \mathrm{XO}_{3}+3 \mathrm{H}_{2} \mathrm{O}
$$

A direct in situ reduction of selenium using aqueous DMF or sodium formaldehydesulfoxylate followed by the reaction with lead acetate afforded $\mathrm{PbSe}$ powder [53]. $\mathrm{NiSe}_{2}$ has been prepared by mixing metallic nickel and elemental selenium in mercaptoethanol at room temperature for a prolonged period resulting in a rust-coloured solution, which upon annealing at $350{ }^{\circ} \mathrm{C}$ under a nitrogen atmosphere produced the phase-pure product [54]. The material is an efficient hydrogen evolution reaction catalyst. The reaction of selenium or tellurium and iron(II) bromide in octane-9enylamine ("oleylamine") at $170^{\circ} \mathrm{C}$ resulted in the formation of $\mathrm{FeE}_{2}(\mathrm{E}=\mathrm{Se}, \mathrm{Te})$ nanocrystals [55]. The amine acted as a solvent and as a reducing agent for the chalcogen. The iron dichalcogenides have attractive electronic properties and can have utility in different device applications.

Hydrazine can also be utilized in the reduction of selenium and tellurium [51,56]. The concurrent treatment of the solution with silver nitrate yielded $\mathrm{Ag}_{2}$ Se nanowires [56]. 


\subsection{Selenium halogenides}

Elemental selenium can conveniently be converted to $\mathrm{Se}_{2} \mathrm{Cl}_{2}$ or $\mathrm{Se}_{2} \mathrm{Br}_{2}$ by mixing the element with $\mathrm{SeCl}_{4}$ or $\mathrm{Br}_{2}$, respectively, in a suitable stoichiometric ratio [57,58]. The reaction with $\mathrm{SO}_{2} \mathrm{X}_{2}(\mathrm{X}=$ $\mathrm{Cl}, \mathrm{Br}$ ) in THF affords $\mathrm{SeX}_{2}$ [59]. A more detailed description of selenium halogenides in synthetic applications is presented in Chapter 2.

\subsection{Heterocyclic selenium sulfides}

Crystalline solid solutions of selenium sulfides $\mathrm{Se}_{n} \mathrm{~S}_{8-n}$ can be produced by melting the elements in vacuo, quenching the molten mixtures, and extracting the quenched melt with $\mathrm{CS}_{2}$ followed by crystallization [45]. The composition of the products has been established by ${ }^{77} \mathrm{Se}$ NMR spectroscopy [60] (see Figure 4). 

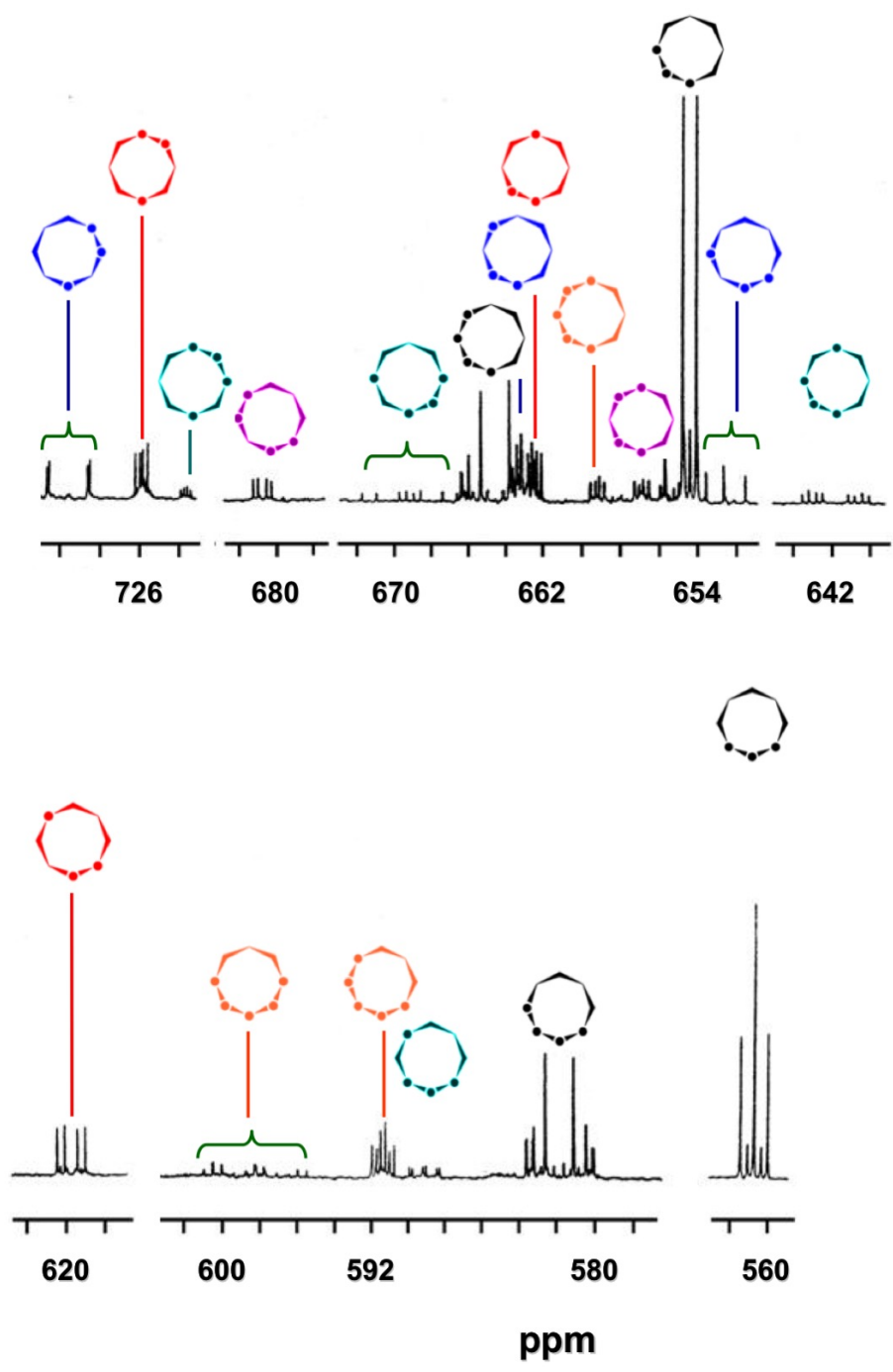

Figure 4. ${ }^{77} \mathrm{Se}$ NMR spectrum of the $\mathrm{CS}_{2}$ solution of quenched sulfur-selenium melt involving ${ }^{77} \mathrm{Se}-$ enriched selenium (enrichment $92 \%$ ) [60,61]. The selenium content in the molten mixture of sulfur and selenium is $30 \mathrm{~mol} \%$ of selenium. The resonances from different individual $\mathrm{Se}_{n} \mathrm{~S}_{8-n}$ species have been shown in different colours. The closed circles indicate selenium atoms and the empty corners sulfur atoms. (Reproduced with permission from Laitinen RS, Oilunkaniemi R. Catenated Compounds: Group 16 (Se, Te). Laitinen RS, Oilunkaniemi R. Catenated compounds group 16 (Se, Te). In Poeppelmeier, K, Reedijk J. Eds. Comprehensive Inorganic Chemistry II, $2^{\text {nd }}$ Ed., Elsevier, Amsterdam 2013, pp 197-231. Copyright 2013 Elsevier SA).

It was deduced that the main components in the $\mathrm{CS}_{2}$ solutions of the crystalline phases extracted from quenched molten mixtures of sulfur and selenium are sulfur-rich $\mathrm{SeS}_{7}$ and 1,2-Se $\mathrm{S}_{6}$ ring molecules even in mixtures of high initial selenium content [60]. Other identified main species are 1,2,3-Ses $\mathrm{S}_{5}$, 1,2,3,4-Se $\mathrm{S}_{4}, 1,2,3,4,5-\mathrm{Se}_{5} \mathrm{~S}_{3}, 1,2,3,4,5,6-\mathrm{Se}_{6} \mathrm{~S}_{2}$, and $\mathrm{Se}_{8}$, in which the number of homonuclear bonds is maximized. 


\subsection{Homopolyatomic selenium cations}

Elemental selenium can be oxidized to homopolyatomic cations in super acidic media, in acidic melts, and in liquid $\mathrm{SO}_{2}[1,62]$. Suitable oxidizing agents are $\mathrm{AlCl}_{3}, \mathrm{AsF}_{5}, \mathrm{SbCl}_{5}, \mathrm{BiCl}_{5}$, and transition metal halogenides $\mathrm{OsF}_{6}, \mathrm{IrF}_{6}, \mathrm{PtF}_{6}, \mathrm{VCl}_{6}, \mathrm{ZrCl}_{6}, \mathrm{HfCl}_{6}, \mathrm{NbCl}_{6}, \mathrm{TaCl}_{6}$, and $\mathrm{WX}_{6}, \mathrm{ReX}_{6}(\mathrm{X}=\mathrm{F}, \mathrm{Cl})$. In addition, $\mathrm{VOCl}_{3}, \mathrm{NbOCl}_{3}$, and $\mathrm{WOCl}_{4}$ can also be used as oxidizing agents. Recently, the selenium cations have also been prepared using chemical vapour transport techniques [63] and ionic liquids [62]. The known homopolyselenium cations include $\mathrm{Se}_{4}{ }^{2+}, \mathrm{Se}_{8}{ }^{2+}$, and $\mathrm{Se}_{10}{ }^{2+}$, but no applications of these species in synthesis have been reported.

\subsection{Triorganylphospine selenides}

Selenium and organic polyselenides react with phosphines yielding phosphine selenides $\mathrm{R}_{3} \mathrm{PSe}$. The reaction with phosphines is often used for abstracting selenium atoms from a polyselenium chain, as exemplified by the formation of [ $\left.\mathrm{TiCp}_{2}\left(\mu-\mathrm{Se}_{2}\right)_{2} \mathrm{TiCp}_{2}\right]$ from $\left[\mathrm{TiCp}_{2} \mathrm{Se}_{5}\right][41]$ (eq. 4).

$$
2\left[\mathrm{TiCp}_{2} \mathrm{Se}_{5}\right]+6 \mathrm{Ph}_{3} \mathrm{P} \quad \rightarrow \quad\left[\mathrm{TiCp}_{2}\left(\mu-\mathrm{Se}_{2}\right)_{2} \mathrm{TiCp}_{2}\right]+6 \mathrm{Ph}_{3} \mathrm{PSe}
$$

The interaction of elemental selenium with phosphines [64] is exemplified by the one-pot synthesis of diselenophosphinic selenoesters [65]. A more detailed discussion of the preparation and application of phosphorus-selenium reagents is presented in Chapter 5.

\subsection{Grignard and organyllithium reagents}

Elemental selenium reacts with Grignard reagents [66] or with organyllithium reagents [67] in dry THF to afford selenolates $\mathrm{RSe}^{-}(\mathrm{R}=$ organyl group) (eqs. 5 and 6$)$. The nature of the organic substituent is dependent on the substituent in the Grignard reagent. Upon oxidation, the selenolates 
can be converted to organyl diselenides, which are themselves convenient reagents in synthetic chemistry (see Chapters 5-11) [66-68]. There are several methods to carry out the oxidation. The best yields have been observed by use of potassium hexacyanidoferrate(III) $[67,68]$ (eq. 7).

$$
\begin{array}{lll}
2 \mathrm{Se}+2 \mathrm{RMgBr} & \rightarrow & 2 \mathrm{RSe}^{-}+2 \mathrm{Mg}^{2+}+2 \mathrm{Br}^{-} \\
\mathrm{Se}+\mathrm{RLi} & \rightarrow & \mathrm{RSe}^{-}+\mathrm{Li}^{+} \\
2 \mathrm{RSe}^{-}+2\left[\mathrm{Fe}(\mathrm{CN})_{6}\right]^{3-} & \rightarrow & \mathrm{RSeSeR}+2\left[\mathrm{Fe}(\mathrm{CN})_{6}\right]^{4-}
\end{array}
$$

Organyl monoselenides can be prepared from lithium selenolate by treatment with an organyl halogenide (eq. 8). By suitable selection of the organic substituent, a number of different selenides can be produced, as exemplified in refs. 69,70 .

$$
\mathrm{RSe}^{-} \mathrm{Li}^{+}+\mathrm{R}^{\prime} \mathrm{X} \quad \rightarrow \quad \mathrm{RSeR}^{\prime}+\mathrm{Li}^{+} \mathrm{Cl}^{-}
$$

The cyclopentadienyl rings in $\left[\mathrm{V}\left(\mathrm{C}_{5} \mathrm{H}_{5}\right)\left(\mathrm{C}_{7} \mathrm{H}_{7}\right][71]\right.$ or $\left[\mathrm{Fe}\left(\mathrm{C}_{5} \mathrm{H}_{5}\right)_{2}\right]$ [72] can be lithiated followed by the insertion of selenium or tellurium [71,72]. The treatment of the former complex affords dichalcogenides. In the case of the latter, a chain of three chalcogen atoms links the two cyclopentadienyl rings in the same complex (see Figure 5). 
(a)

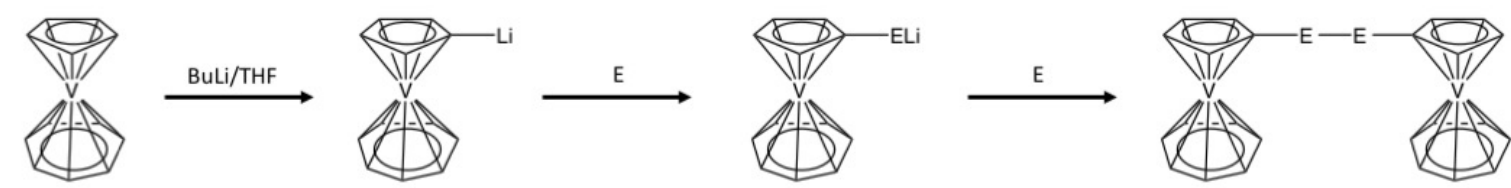

(b)

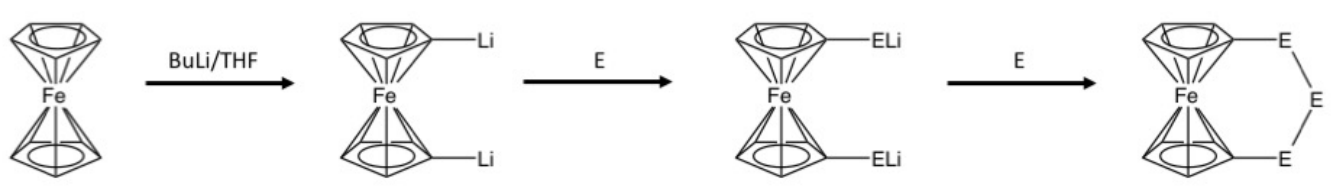

Figure 5. Elemental chalcogens as soft oxidants $(E=S$, Se, Te). Preparation of (a) $\left[\left\{\mathrm{V}\left(\mathrm{C}_{7} \mathrm{H}_{7}\right)\left(\mathrm{C}_{5} \mathrm{H}_{4} \mathrm{E}\right)\right\}_{2}\right][71]$ and $(b)\left[\mathrm{Fe}\left(\mathrm{C}_{5} \mathrm{H}_{4} \mathrm{E}\right)_{2} \mathrm{E}\right][72]$.

\subsection{Selenium and heavy group 14 reagents}

Stable silanechalcogenones containing a terminal $\mathrm{Si}=\mathrm{E}(\mathrm{E}=\mathrm{Se}, \mathrm{Te})$ functionality can be formed by the reaction of the amidinate-stabilized silicon(II)bis(trimethylsilyl)amide and selenium or tellurium [73] [see Figure 6(a)] and germaneselones by the abstraction of selenium from $\mathrm{RR}^{\prime} \mathrm{GeSe}_{4}$ with triphenylphosphine [74]. 1,2,3,4,5-tetraselenagermolane can be prepared by lithiation of $\mathrm{RR}^{\prime} \mathrm{GeH}_{2}$ followed by the treatment with elemental selenium [see Figure 6(b)]. The formation of RR'GeSe in reasonable yields requires very bulky organic substituents. 
(a)

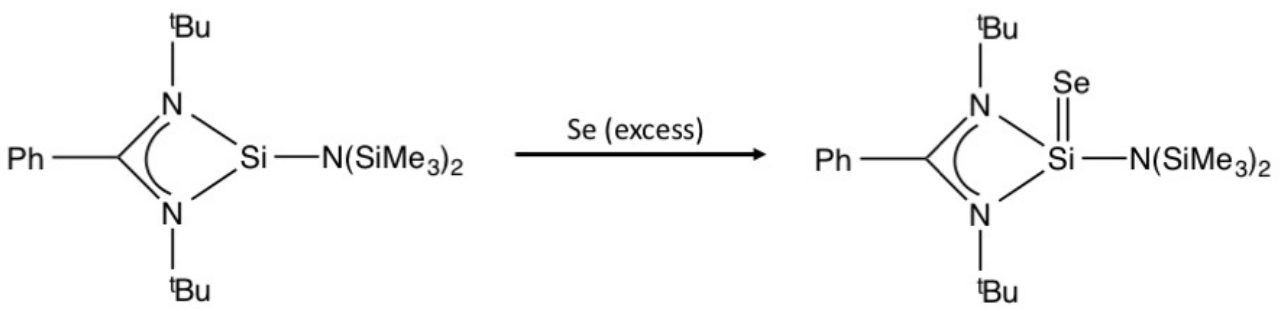

(b)

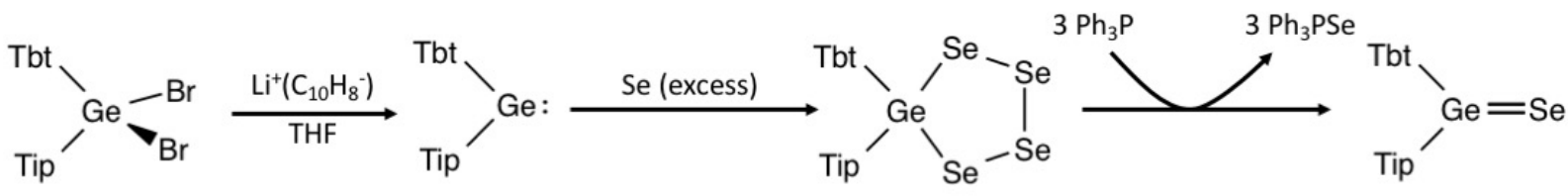

Tbt $=2,4,6$-tris[bis(trimethylsilyl)methyl]phenyl Tip = 2,4,6-triisopropylphenyl

Figure 6. Synthesis of (a) $\mathrm{PhC}\left(\mathrm{N}^{t} \mathrm{Bu}\right)_{2} \mathrm{Si}(\mathrm{Se}) \mathrm{N}\left(\mathrm{SiMe}_{3}\right)_{2}$ [72] and (b) (Tbt)(Tip)GeSe [73].

Another application of germylenes in the formation of a $\mathrm{Ge}=\mathrm{Se}$ double bond involves the oxidative addition of elemental selenium to a Ge(II) center [75,76] (see Figure 7). The actual reactant, aminotroponiminato(trimethylsilathio)germylene was obtained by the reaction of the germylene monochloride with $\mathrm{Li}^{+}\left(\mathrm{SSiMe}_{3}\right)$ [75]. When treated with selenium, the oxidative addition was followed by a virtually quantitative condensation step (see Figure 8$)$. By contrast, when $\mathrm{Li}^{+}\left(\mathrm{SSiMe}_{3}{ }^{-}\right.$ ) was substituted by $\mathrm{Li}^{+}\left(\mathrm{OSiR}_{3}{ }^{-}\right)(\mathrm{R}=\mathrm{Me}, \mathrm{Ph})$, only a clean single-stage oxidative addition took place [76]. 


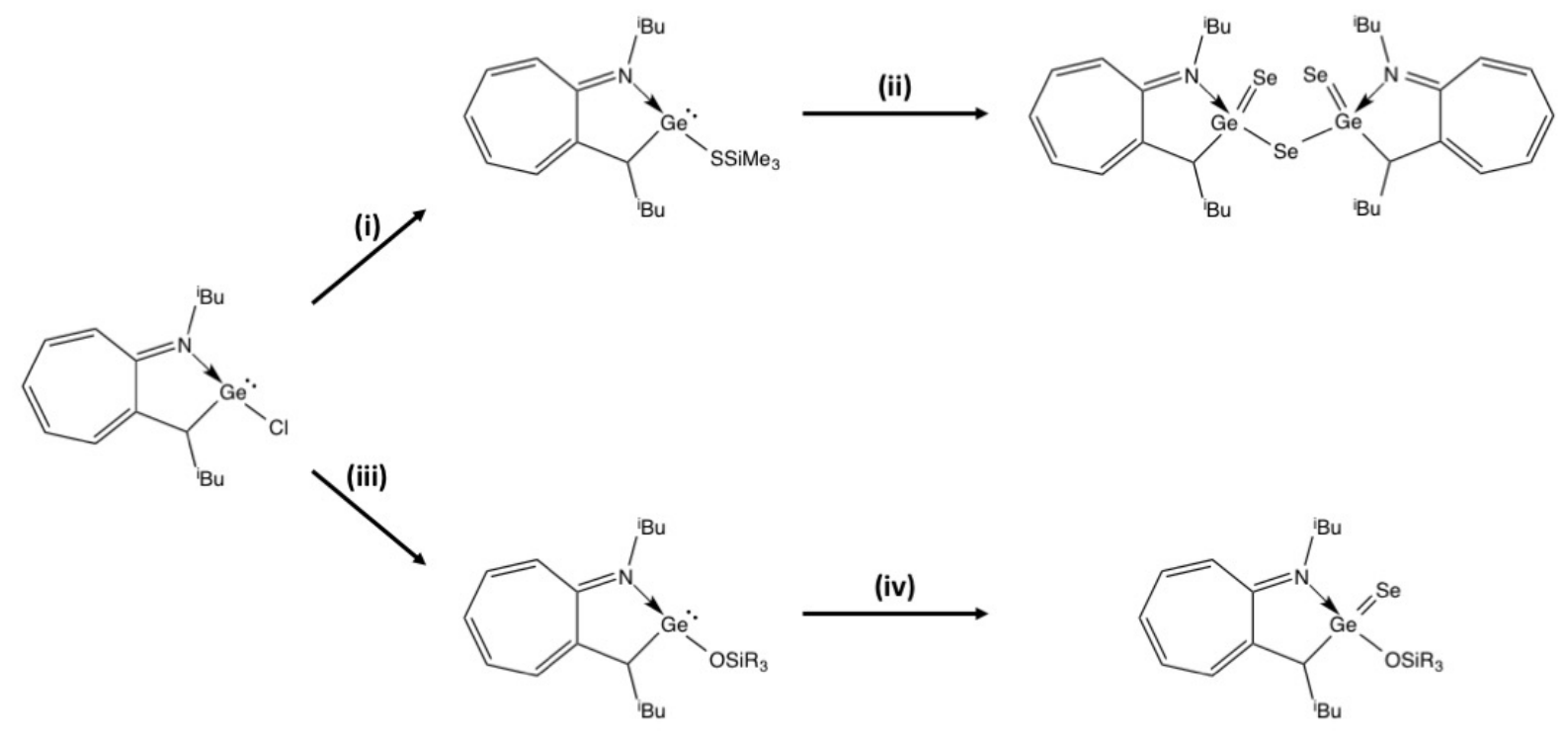

Figure 7. Oxidative addition of selenium to the Ge(II) center [75,76]. (i) $2 \mathrm{Li}^{+}\left(\mathrm{SSiMe}_{3}{ }^{-}\right) \cdot \mathrm{THF} / \mathrm{h}$ exane $0{ }^{\circ} \mathrm{C}$, (ii) $\mathrm{Se} / \mathrm{THF}$ r.t., (iii) $\mathrm{Li}^{+}\left(\mathrm{OSiR}_{3}^{-}\right) /$toluene r.t. $(\mathrm{R}=\mathrm{Me}, \mathrm{Ph})$, (iv) $\mathrm{Se} / \mathrm{THF}$ r.t.

\subsection{Selenium-boron chemistry}

Organic diborylenes $\mathrm{RB}=\mathrm{BR}$ can be stabilized by bulky substituents such as Tbt $\{2,3,6$ tris[bis(trimethylsilyl)methyl]phenyl\} [77]. Selenium can be inserted into the boron-boron double bond under the influence of uv-radiation. The formal reactant is $\mathrm{TbtB}(\mathrm{SeMe})_{2}$, but it has been postulated that upon irradiation the reactive component is the borylene Tbt-B:, which is formed upon elimination of $\mathrm{Me}_{2} \mathrm{Se}_{2}$ from $\mathrm{TbtB}(\mathrm{SeMe})_{2}$. The monomer Tbt-B: dimerizes forming Tbt-B=B-Tbt, which then reacts with elemental selenium [77]. It has very recently been shown that that the diboryne $\mathrm{RB} \equiv \mathrm{BR}(\mathrm{R}=1$,2-bis(2,6-diisopropylphenyl)imidazol-2-ylene) reacts with an excess of elemental selenium to form $\mathrm{RB}\left(\mu-\mathrm{Se}_{2}\right)_{2}(\mu-\mathrm{Se}) \mathrm{BR}[78]$. By choice of suitable organic groups, it was shown that the diborylene RR'B=BRR' ( $\mathrm{R}=$ 1,3-dimethylimidazol-2-ylidene, R' = 5-trimethylsilyl-thien-2-yl), reacts with elemental selenium yielding diboraselenirane [79]. All three reactions are compared in Figure 8. 
(a)
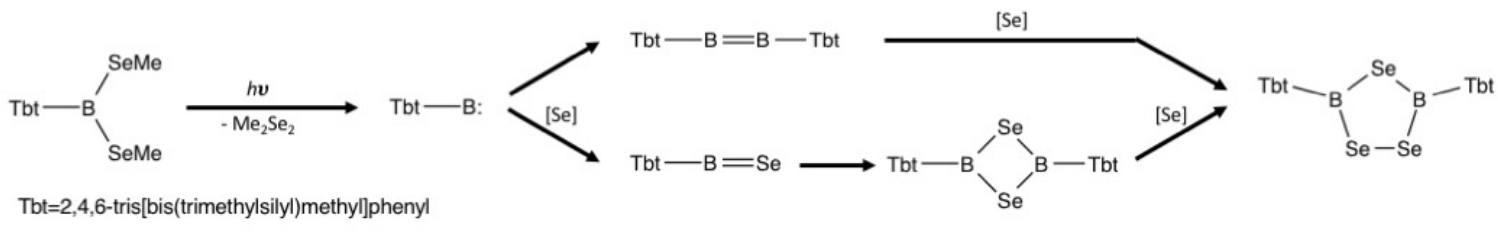

(b)<smiles>O=[N+]([O-])N1C=CN([O+])C1C#CC1N([O+])C=CN1[O+]</smiles><smiles>C[14CH2][14CH2][14CH2][14CH2][14CH2][14CH2]</smiles>

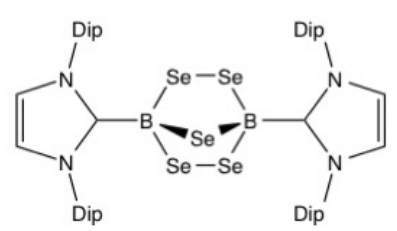

Dip=1,3-diisopropylphenyl

(c)<smiles></smiles>
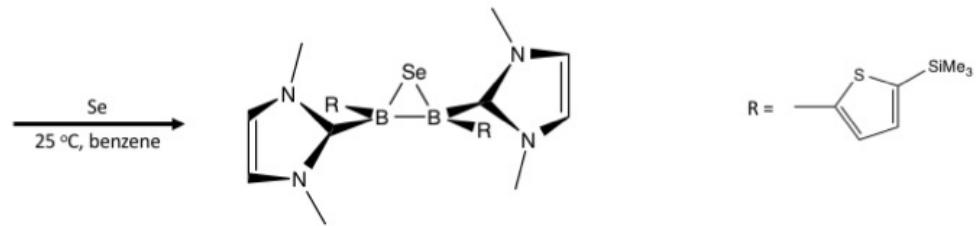

Figure 8. Reactions of boron-boron multiple bonds with elemental selenium. (a) Ref. 77. (b) Ref. 78. (c) Ref. 79.

\subsection{Transition metal selenides}

Transition metal and main group polyselenides can conveniently be prepared and crystallized by utilizing the molten salt technique [80-82], in which alkali metal polychalcogenides are used as molten fluxes. The reactions are conducted in the temperature range $200-450{ }^{\circ} \mathrm{C}$ to ensure the stability of the produced materials. Transition metal polyselenides generally have extended 1D or 2D structures- There is a recent review on the synthesis of lanthanoid-containing heterometallic chalcogenides, which have been prepared by utilizing alkali metal polychalcogenide flux [83]. Polynuclear selenium- and tellurium-containing complexes are discussed in more detail in Chapter 10. 


\section{Elemental tellurium}

\subsection{General}

Though the chemistry of tellurium and its compounds is mainly similar to that of selenium, there are also notable differences [3]. The general bonding features are significantly different compared to those of the lighter chalcogen congeners. The homonuclear Te-Te bond energies are lower $(149 \mathrm{~kJ}$ $\left.\mathrm{mol}^{-1}\right)$ than those involving selenium $\left(192 \mathrm{~kJ} \mathrm{~mol}^{-1}\right)$ or sulfur $\left(266 \mathrm{~kJ} \mathrm{~mol}^{-1}\right)$. The heteronuclear E-X bonds $(\mathrm{E}=\mathrm{Te}, \mathrm{Se}, \mathrm{S})$ follow the same trend (see ref. 84 for the compilation of bond energies). Consequently, tellurium compounds are generally more labile and more air- and moisture-sensitive. Tellurium also has a weaker tendency for multiple bonding than selenium and sulfur.

By contrast, tellurium shows higher propensity to hypervalency [85] and secondary bonding interactions (SBI) [86]. This is due to the decreased energy difference between $\sigma(\mathrm{Te}-\mathrm{X})$ and $\sigma^{*}(\mathrm{Te}-$ $\mathrm{X})$ orbitals and stronger $\mathrm{n}(\mathrm{X}) \rightarrow \sigma^{*}(\mathrm{Te}-\mathrm{X})$ interactions. This accounts for stronger intermolecular interactions in tellurium compounds compared to those in related selenium and sulfur species. Electrostatic effects further enhance the strength of the secondary bonding interactions due to the existence of $\sigma$-holes in tellurium (see ref. 3 and references cited therein).

An overview of the use of elemental tellurium as a reagent is presented in Figure 9 with some illustrative examples. 


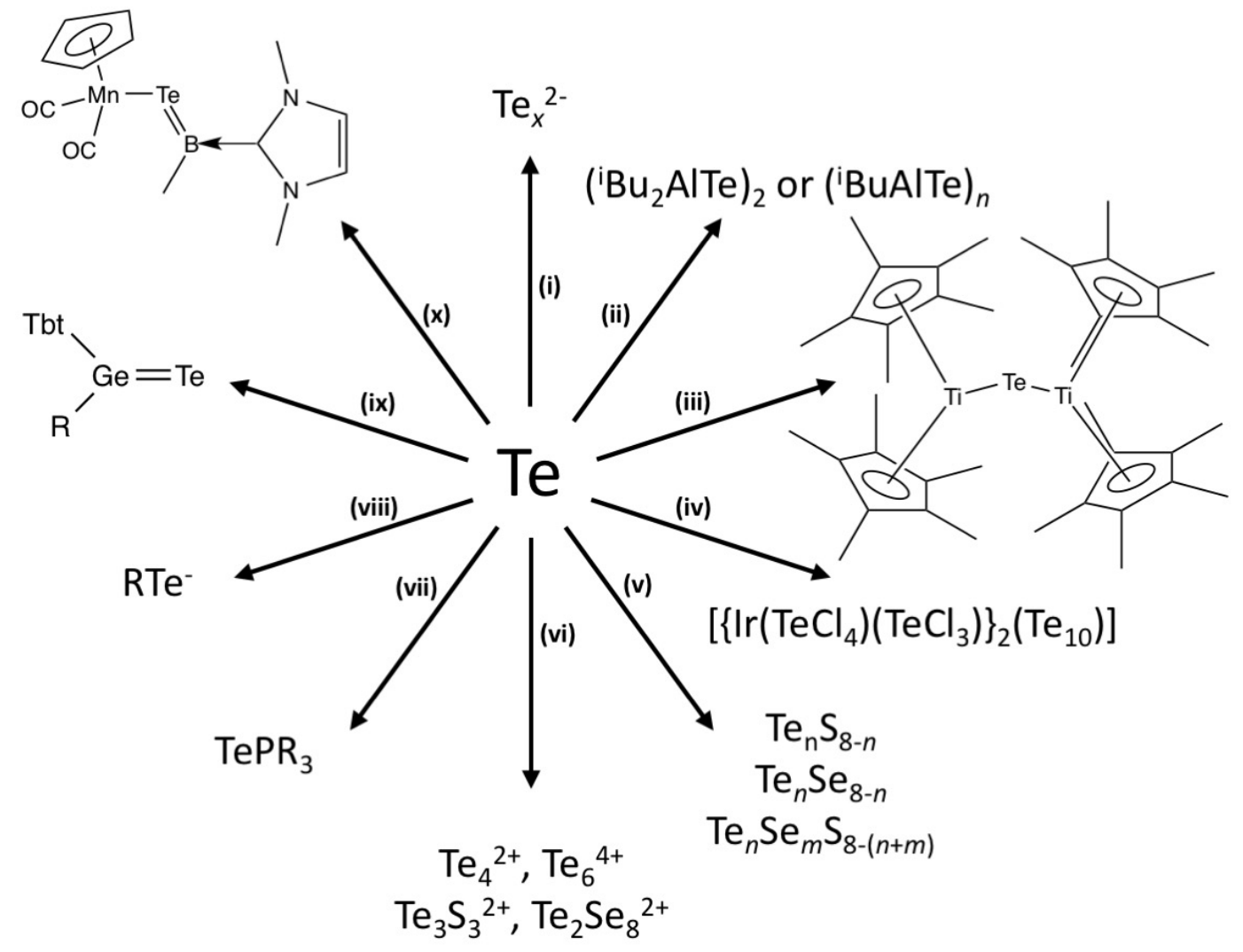

Figure 9. Illustrative examples on the reactivity of elemental tellurium. (i) $\mathrm{M} / \mathrm{NH}_{3}(\mathrm{l})(\mathrm{M}=\mathrm{Li}, \mathrm{Na}$, $\mathrm{K}$ ), $\mathrm{NaBH}_{4} / \mathrm{THF}$ or $\mathrm{Li}\left[\mathrm{AlEt}_{3} \mathrm{H}\right]$, (ii) ${ }^{\mathrm{B}} \mathrm{Bu}_{2} \mathrm{AlH} /$ toluene, (iii) $\left[\mathrm{Ti}\left(\mathrm{C}_{5} \mathrm{Me}_{5}\right)_{2} \mathrm{TiH}\right] /$ toluene, (iv) $\mathrm{Te}$, Ir, and $\mathrm{TeCl}_{4} / 250^{\circ} \mathrm{C}$, (v) molten mixtures of tellurium, selenium, and sulfur, (vi) $\mathrm{SbF}_{5} / \mathrm{SO}_{2}$ (l), (vii) $\mathrm{PR}_{3}(\mathrm{R}$ = alkyl), (viii) $\mathrm{RMgX} / \mathrm{THF}\left(\mathrm{X}=\mathrm{Cl}, \mathrm{Br}\right.$ ) or $\mathrm{RLi} / \mathrm{THF}$, (ix) $\mathrm{Ge}(\mathrm{Tbt}) \mathrm{RGe}\left(\mathrm{Ph}_{2} \mathrm{C}_{2}\right) /$ benzene, (x) $\left[\mathrm{MnCp}(\mathrm{CO})_{2}\left\{\mathrm{~EB}\left({ }^{\mathrm{t}} \mathrm{Bu}\right)\left(\mathrm{C}[\mathrm{NMe}]_{2} \mathrm{C}_{2} \mathrm{H}_{2}\right)\right\}\right]$.

\subsection{Anionic tellurides}

As in the case of selenium, the reduction of tellurium to telluride anions is the most convenient method for initial introduction of tellurium into reaction systems. The reduction has been carried out in a similar fashion to selenium, i.e. with alkali metals in liquid ammonia $[20,21,23]$ or in dipolar aprotic solutions [27], sodium tetrahydridoborate [87-91], and lithium triethylhydridoaluminate $[92,93]$. As the effects due to hypervalence and secondary bonding interactions are more significant in the case of tellurium than with the lighter chalcogen congeners $[85,86]$, tellurium shows more 
diverse polyanion chemistry than sulfur and selenium. Polytellurides can therefore exhibit charges that deviate from -2 .

In addition to selenide and polyselenide anions, Björgvinsson and Schrobilgen [23] have also explored the product distribution of tellurium-containing chalcogenide and polychalcogenide anions in the liquid ammonia or in the ethylene diamine solution using ${ }^{125} \mathrm{Te}$ and ${ }^{77} \mathrm{Se} \mathrm{NMR}$ spectroscopy. 2,2,2-crypt was added into the solutions to complex with the alkali metal cation and ensure narrow NMR resonances. As the stoichiometry of the starting materials was varied (see eq. 9), the presence of $\mathrm{Te}_{n}{ }^{2-}(\mathrm{n}=1-4)$ and $\mathrm{HTe}^{-}$was inferred. The synthesis of stable salts of $\mathrm{HE}^{-}(\mathrm{E}=\mathrm{Se}, \mathrm{Te})$ in ionic liquids using large counter-cations has also recently been reported [94]. Their use in syntheses has been discussed in Chapter 8.

$$
2 \mathrm{~K}+n \mathrm{Te} \quad \rightarrow \quad \mathrm{K}_{2} \mathrm{Te}_{n}
$$

Polytelluride and polyselenide anions could also be prepared from the stoichiometric amounts of $\mathrm{K}_{2} \mathrm{E}$ and $\mathrm{E}(\mathrm{E}=\mathrm{Te}, \mathrm{Se})$ (eq. 10). In the case of mixtures of selenium and tellurium, the reaction affords also a series of tellurium selenide anions. The formation of open-chain potassium-cryptated salts of $\mathrm{TeSe}_{2}{ }^{2-}$ and $\mathrm{Te}_{x} \mathrm{Se}_{4-x}{ }^{2-}$, as well as pyramidal $\mathrm{TeSe}_{3}{ }^{2-}$ has been reported [95].

$$
\mathrm{K}_{2} \mathrm{E}+n \mathrm{E} \quad \rightarrow \quad \mathrm{K}_{2} \mathrm{E}_{n+1}
$$

The mixing of $\mathrm{Te}_{n}{ }^{2-}$ and $\mathrm{Se}_{n}{ }^{2-}$, which have been prepared upon reduction by metallic lithium in liquid ammonia, yielded in addition to open-chain $\mathrm{Te}_{2} \mathrm{Se}_{2}{ }^{2-}$ and pyramidal $\mathrm{TeSe}_{3}{ }^{2-}$ anions also the spirocyclic anion $\mathrm{TeSe}_{10}{ }^{2-}$, and extended anionic networks $\left(\mathrm{Te}_{3} \mathrm{Se}_{6}\right)_{n}{ }^{2 n-}$ and $\left(\mathrm{Te}_{3} \mathrm{Se}_{7}\right)^{2 n-}[96]$. 
Basmadijan et al. [87] have shown that the distribution of the reduction products $\mathrm{HTe}^{-}, \mathrm{Te}^{2-}$, and $\mathrm{Te}_{2}^{2-}$ upon treating elemental tellurium with sodium tetrahydridoborate $\mathrm{NaBH}_{4}$ in aqueous solution depends on the molar ratio of the reactants as well as on the $\mathrm{pH}$ of the solution. The reduction by sodium tetrahydridoborate is generally applied in the production of various binary tellurides [88-90] such as cadmium telluride quantum dots [90] and lead telluride nanocrystals [88].

\subsection{Derivatives of anionic tellurides}

Lithium ethylhydridoaluminate is an equally useful reducing agent for elemental tellurium as for elemental selenium and sulfur $[92,93]$. The reaction of thus formed $\mathrm{Te}_{x}{ }^{2-}$ with trialkylsilyl chloride affords bis(trialkylsilyl)tellurides $\left(\mathrm{R}_{3} \mathrm{Si}\right)_{2} \mathrm{Te}$ [92] (see eq. 11), which are convenient reagents in synthetic inorganic chemistry (for examples, see refs. 97, 98), in organic chemistry, as exemplified in refs. 92, 99, in coordination chemistry $[100,101]$, and as a precursor for producing thin films by the ALD technique [102]. The reaction of tellurides with $\mathrm{Me}_{3} \mathrm{SiCl}$ is slow and the yield is only moderate. However, a better result can be obtained if ${ }^{\mathrm{t}} \mathrm{BuMe}{ }_{2} \mathrm{SiCl}$ is utilized instead of $\mathrm{Me}_{3} \mathrm{SiCl}$ [92].

$$
1 / x \mathrm{Te}_{x}^{2-}+2 \mathrm{R}_{3} \mathrm{SiCl} \quad \rightarrow \quad\left(\mathrm{R}_{3} \mathrm{Si}\right)_{2} \mathrm{Te}+2 \mathrm{Cl}^{-}
$$

The reduction of tellurium by lithium triethylhydridoaluminate in THF followed by treatment with $\mathrm{TeX}_{4}(\mathrm{X}=\mathrm{Cl}, \mathrm{Br})$ (eq. 12) affords $\mathrm{Te}_{2} \mathrm{X}_{2}$ [103]. Ditellurium dichloride is a yellow liquid, which, though unstable, can be stored for hours in an inert atmosphere. Ditellurium dibromide is orange-red liquid, which is more stable than the corresponding chloride. These tellurium(I) reagents have been used to prepare the heteroatomic rings $1,2-\mathrm{Te}_{2} \mathrm{~S}_{5}$ and $1,2-\mathrm{Te}_{2} \mathrm{Se}_{5}$ by reactions with $\left[\mathrm{Ti}\left(\mathrm{C}_{5} \mathrm{H}_{5}\right)_{2} \mathrm{E}_{5}\right](\mathrm{E}$ $=\mathrm{S}, \mathrm{Se})$ (eq. 13). 


$$
\begin{aligned}
& \mathrm{Te}_{x}{ }^{2-}+x \mathrm{TeX}_{4} \quad \rightarrow \quad x \mathrm{Te}_{2} \mathrm{X}_{2}+2 x \mathrm{X}^{-}(\mathrm{X}=\mathrm{Cl}, \mathrm{Br}) \\
& {\left[\mathrm{Ti}\left(\mathrm{C}_{5} \mathrm{H}_{5}\right)_{2} \mathrm{E}_{5}\right]+\mathrm{Te}_{2} \mathrm{X}_{2} \quad \rightarrow \quad 1,2-\mathrm{Te}_{2} \mathrm{E}_{5}+\left[\mathrm{Ti}\left(\mathrm{C}_{5} \mathrm{H}_{5}\right)_{2} \mathrm{X}_{2}\right]}
\end{aligned}
$$

$\mathrm{Na}_{2} \mathrm{Te}$ or $\mathrm{NaTeH}$ can also be utilized in the syntheses of tellurium macrocycles, as reported by Panda [104].

\subsection{Tellurium-containing chalcogen rings}

Tellurium forms both binary and tertiary heterocyclic molecules with selenium and sulfur, though the systems involving tellurium are much simpler than the binary system of selenium and sulfur (see Section 2.4) $[45,61]$. As in the case of the $\mathrm{Se}_{n} \mathrm{~S}_{8-n}$ molecules, the eight-membered rings $\mathrm{TeS}_{7}$ and 1,2, 1,3-, and 1,4- $\mathrm{Te}_{2} \mathrm{~S}_{6}$ are formed in the binary melt [105], while the ternary species 1,2-, 1,3-, 1,4-,

and 1,5-TeSeS 6 are observed in sulfur-rich, sulfur-selenium-tellurium melts, as indicated by the ${ }^{125} \mathrm{Te}$ NMR spectrum of a molten mixture of sulfur (97 mol \%), selenium (1,5 mol \%), and tellurium (1.5 mol \%) shown in Figure 10. 


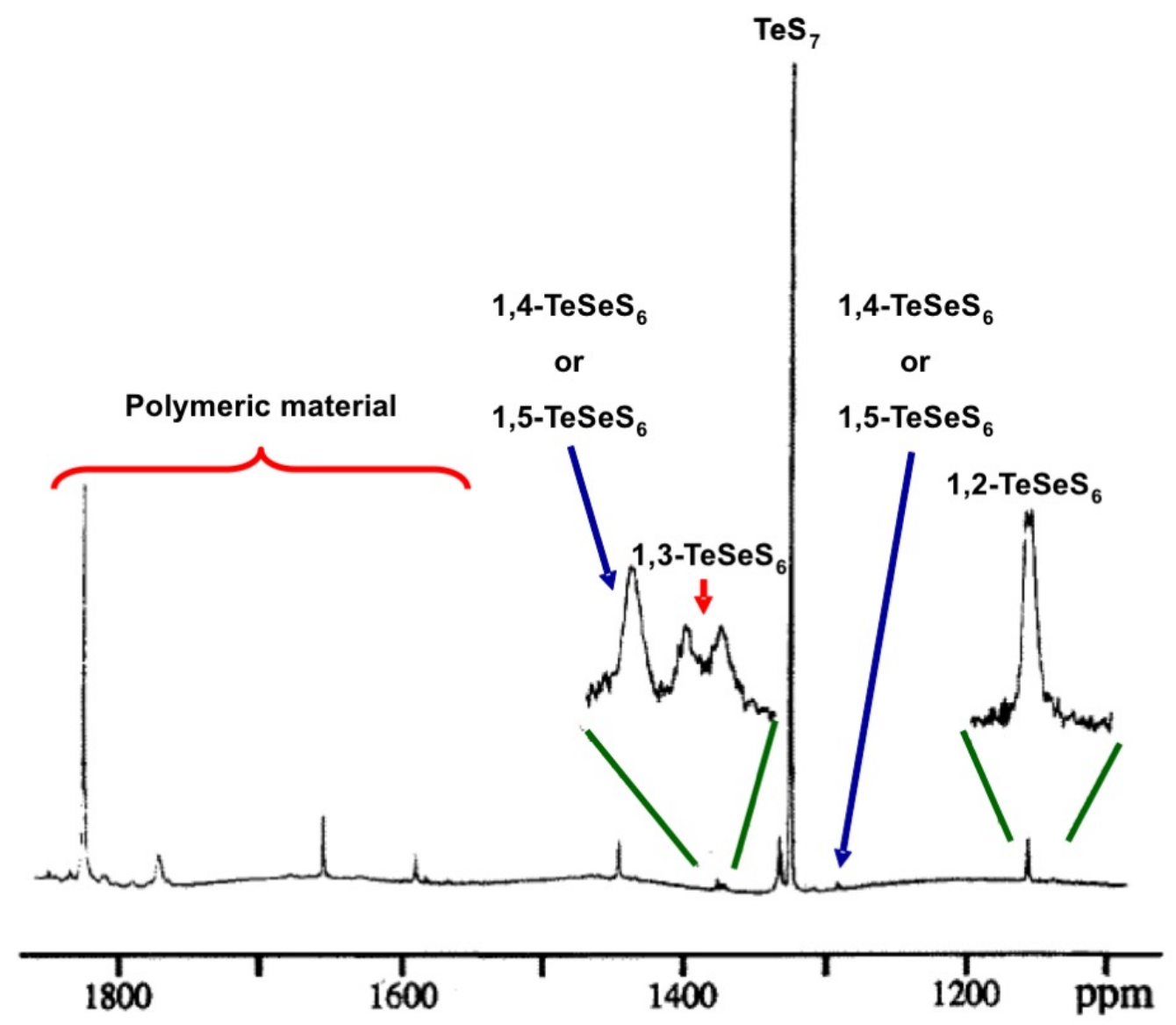

Figure 10. ${ }^{125} \mathrm{Te}$ NMR spectrum of ternary sulfur-selenium-tellurium melt containing ${ }^{77} \mathrm{Se}$-enriched selenium (1.5 mol\%) and ${ }^{125}$ Te-enriched tellurium $(1.5 \mathrm{~mol} \%)$ (enrichment in both cases $\left.92 \%\right)$. The spectrum has been recorded at $145{ }^{\circ} \mathrm{C}$ [105] (Adapted with permission from Chivers T, Laitinen RS, Schmidt KJ, Taavitsainen, J. Inorg Chem 1993, 32, 337-340. Copyright 1993 American Chemical Society).

\subsection{Homopolyatomic tellurium cations}

Tellurium can be oxidized to several different homopolyatomic cations in the same fashion as selenium $[1,62,63]$, e.g. $\mathrm{Te}_{4}{ }^{2+}, \mathrm{Te}_{6}{ }^{2+}, \mathrm{Te}_{6}{ }^{4+}, \mathrm{Te}_{8}{ }^{2+}, \mathrm{Te}_{8}{ }^{4+}$, etc. However, applications of these cations for the synthesis of other tellurium compounds have not been reported.

\subsection{Triorganylphosphine tellurides}

Triorganylphosphine tellurides can be prepared from the corresponding phosphine and elemental tellurium [106,107]. Trialkylphosphine tellurides are sufficiently stable for subsequent synthetic 
work and have been widely used in the synthesis of semi-conducting metal tellurides [108-113]. More detailed discussion on the phosphorus-tellurium chemistry is presented in Chapter 5.

\subsection{Grignard and organyllithium reagents}

As in the case of selenium, both Grignard reagents and organyllithium reagents are efficient in producing organyltellurolates [114], which can easily be oxidized to the corresponding ditellurides that are themselves useful reagents in synthetic inorganic and organic chemistry (for some examples in different areas of chemistry, see refs. 115-118). The reactions of ditellurides are discussed in Chapters 5-11 and the ligand chemistry of tellurolates in Chapter 11.

\subsection{Silane- and germanetellones}

Recent years have seen progress in developing synthetic strategies to prepare silicon-tellurium and germanium tellurium double bonds. A stable dialkylsilylene reacts with elemental tellurium or selenium to form a silanetellone and silaneselone, respectively [119], as shown in Figure 11.
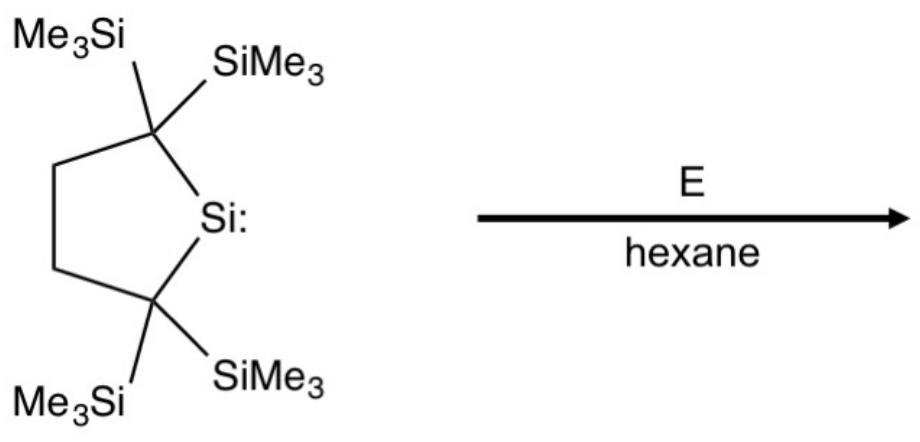

Figure 11. Preparation of silanechalcogenones [119].

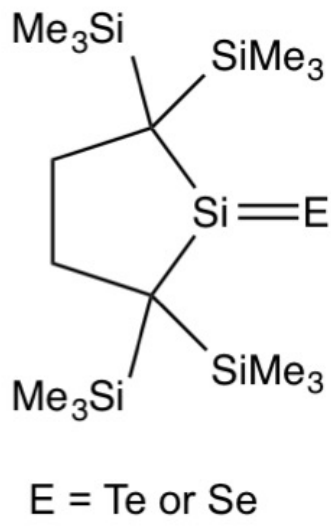

Tokitoh et al. [120] carried out a direct telluration of germylene $\operatorname{Tbt}(\mathrm{R}) \mathrm{Ge}$ : containing very bulky substituents on germanium (Tbt $=2,4,6$-tri[tris(trimethylsilyl)methyl]phenyl; $\mathrm{R}=2,4,6$ triisopropylphenyl or bis(trimethylsilyl)methyl) and obtained thermally stable germanetellones (see 
Figure 12), which were moisture-sensitive. The presence of a $\mathrm{Ge}=\mathrm{Te}$ double bond was verified by the X-ray structure determination. The treatment of the germanetellone with mesitonitrile oxide or 2,3dimethyl-1,3-butadiene resulted in [3+2] or [4+2] cycloaddition products, respectively.

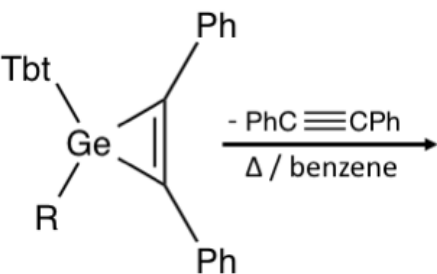

$\left(\mathrm{Me}_{3} \mathrm{Si}\right)_{3} \mathrm{C}$

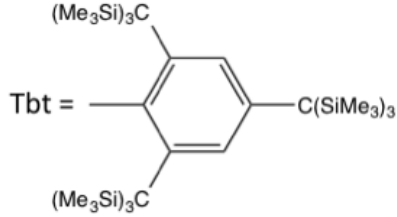<smiles>[R][Ga]Br</smiles><smiles>CCCCC</smiles>

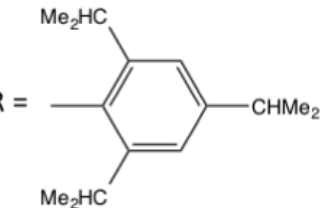

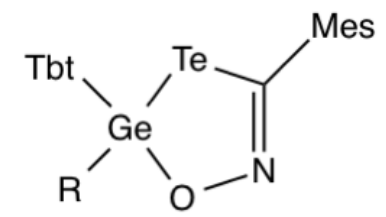<smiles>[R][Ge](Br)=[Te]</smiles>
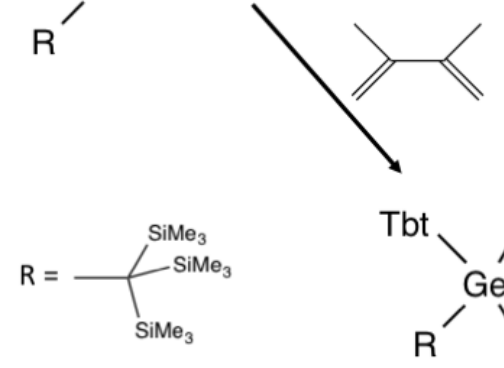

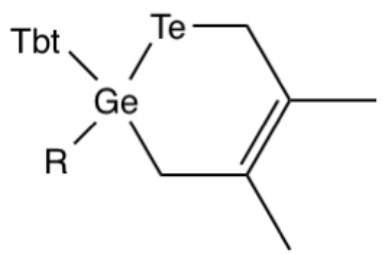

Figure 12. Formation of germanetellone and its cycloaddition reactions [120].

\subsection{Group 13 chemistry with tellurium}

Tellurium is the heaviest element known to form a double bond with boron [121]. The reaction involves the insertion of tellurium into the $\mathrm{Mn}=\mathrm{B}$ bond in the base-stabilized complex $\left[\mathrm{Mn}\left\{=\mathrm{B}\left({ }^{\mathrm{t}} \mathrm{Bu}\right) \mathrm{C}\left[(\mathrm{MeN})_{2}\left(\mathrm{CH}_{2}\right)\right]_{2}\right\}\left(\mathrm{C}_{5} \mathrm{H}_{5}\right)(\mathrm{CO})_{2}\right]$, as shown in Figure 13. Lighter chalcogens react in a similar fashion. 


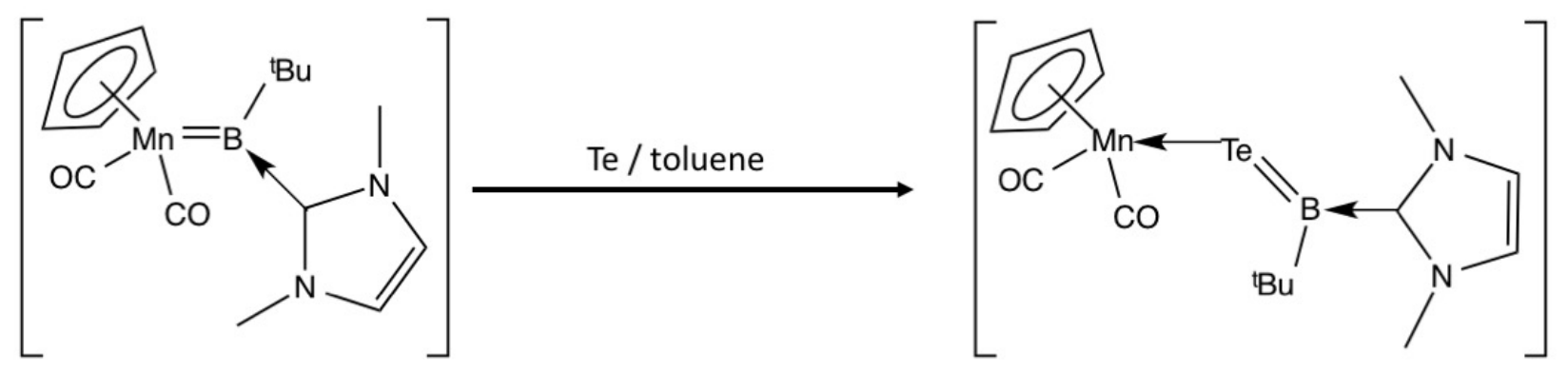

Figure 13. The formation of a $B=T e$ double bond [121].

An excess of elemental tellurium in refluxing toluene reacts with $\mathrm{M}\left({ }^{\mathrm{t}} \mathrm{Bu}\right)_{3}(\mathrm{M}=\mathrm{Al}, \mathrm{Ga})$ to form the cubane $\left[\mathrm{M}\left({ }^{\mathrm{t}} \mathrm{Bu}\right)\left(\mu_{3}-\mathrm{Te}\right)\right]_{4}$ and ${ }^{\mathrm{t}} \mathrm{BuTeTe}{ }^{t} \mathrm{Bu}[122,123]$ (see Figure 14). The structure of the tetrameric cage molecule was deduced by comparison of the spectroscopic properties with those of $\left[\mathrm{M}\left({ }^{\mathrm{t}} \mathrm{Bu}\right)\left(\mu_{3^{-}}\right.\right.$ $\mathrm{Se})]_{4}$ and $\left[\mathrm{M}\left({ }^{\mathrm{t}} \mathrm{Bu}\right)\left(\mu_{3}-\mathrm{S}\right)\right]_{4}$. The crystal structure of $\left[\mathrm{Ga}\left({ }^{\mathrm{t}} \mathrm{Bu}\right)\left(\mu_{3}-\mathrm{S}\right)\right]_{4}$ is known [124].

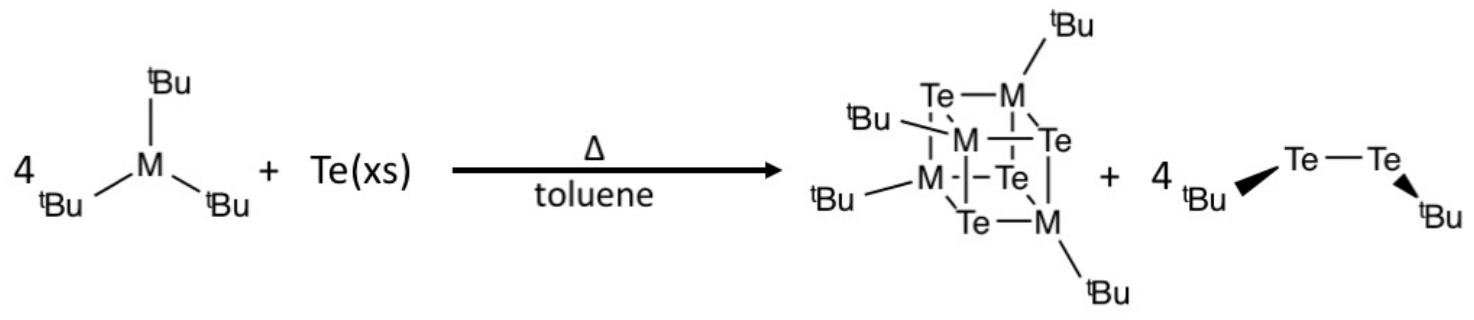

Figure 14. The reaction of $\mathrm{M}\left({ }^{\mathrm{t}} \mathrm{Bu}\right)_{3}(\mathrm{M}=\mathrm{Al}, \mathrm{Ga})$ with an excess of tellurium [122].

Elemental tellurium and selenium also react with diisobutylaluminium hydride ${ }^{\mathrm{i}} \mathrm{Bu}_{2} \mathrm{AlH}$ in toluene at 120-130 ${ }^{\circ} \mathrm{C}$ [125]. Mass spectrometric and NMR spectroscopic information indicated the formation a mixture of the dimer $\left({ }^{\mathrm{i}} \mathrm{Bu}_{2} \mathrm{AlE}\right)_{2}$ and the oligomer $\left({ }^{\mathrm{i}} \mathrm{Bu}_{2} \mathrm{AlE}\right)_{n}$ together with an unspecified product containing carbon, chalcogen, and aluminium. These in situ reagents react with amides to give 
chalcogenamides (see Figure 15). While selenoamides are relatively stable, telluroamides easily decompose.

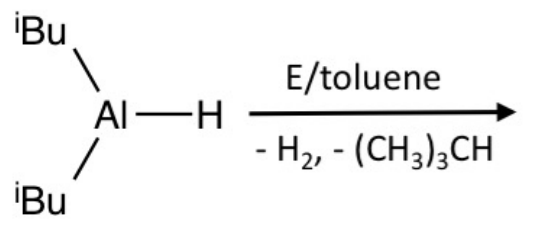

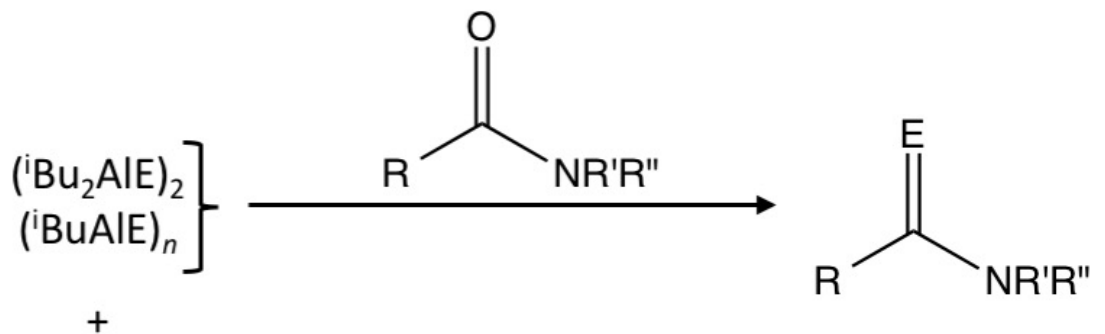

\section{"C,E,Al"}

Figure 15. The reaction of tellurium and selenium with diisobutylaluminium hydride and amides ( $\mathrm{E}$ $=$ Te, Se; R, R', R” = organyl groups) [125].

\subsection{Titanocene chemistry}

Bis(pentamethylpentadienyl)hydridotitanium reacts with tellurium or selenium powder to afford titanium complexes that contain monochalcogenido(2-) or dichalcogenido(2-) ligands (see Figure 16) $[126,127]$.

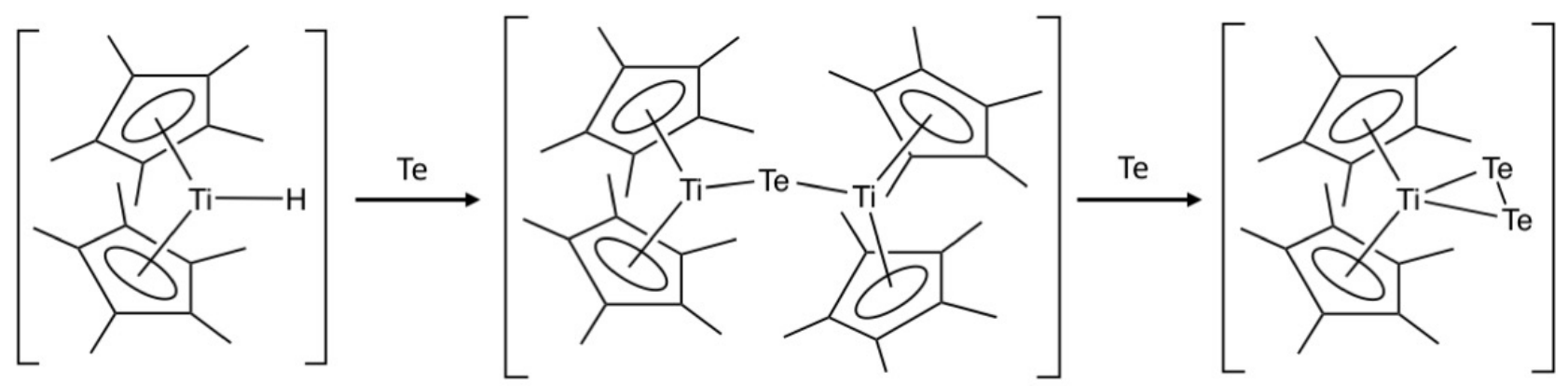

Figure 16. The reaction of $\left[\mathrm{Ti}\left(\mathrm{C}_{5} \mathrm{Me}_{5}\right)_{2} \mathrm{H}\right]$ with tellurium [127].

While both tellurium and selenium react with $\left[\mathrm{Ti}_{(}\left(\mathrm{C}_{5} \mathrm{Me}_{5}\right)_{2} \mathrm{H}\right]$, the reaction proceeds more smoothly in the case of tellurium, if tributylphosphine telluride is used as a tellurium source $[126,127]$. Interestingly, $\left[\mathrm{Ti}\left(\mathrm{C}_{5} \mathrm{Me}_{5}\right)_{2} \mathrm{Te}_{2}\right]$ is mononuclear, while the related complex, which involves the 
methylcyclopentadienyl ligand coordinated to titanium, is dinuclear $\left[\mathrm{Ti}_{(}\left(\mathrm{C}_{5} \mathrm{H}_{4} \mathrm{Me}\right)_{2}(\mu-\right.$ $\left.\left.\mathrm{Te}_{2}\right)_{2} \mathrm{Ti}\left(\mathrm{C}_{5} \mathrm{H}_{4} \mathrm{Me}\right)_{2}\right][96]$. This appears to be due to steric effects.

\subsection{Solid-state and hydrothermal reactions}

Intriguingly, solid-state (hydrothermal) reactions of tellurium with transition metals and tellurium(IV) tetrahalides can produce materials that incorporate unusual homoatomic tellurium rings. For example, prolonged heating of a mixture of elemental tellurium with a late transition metal and tellurium tetrachloride in an evacuated ampoule at $250-300{ }^{\circ} \mathrm{C}$ produces $\left[\left\{\mathrm{M}\left(\mathrm{TeX}_{4}\right)\left(\mathrm{TeX}_{3}\right)\right\}_{2}\left(\mathrm{Te}_{10}\right)\right]$ and, $\left[\left\{\mathrm{M}\left(\mathrm{TeI}_{4}\right)\left(\mathrm{TeI}_{2}\right)\right\}_{2}\left(\mathrm{TeI}_{4}\right)\left(\mathrm{Te}_{2} \mathrm{I}_{2}\right)\left(\mathrm{Te}_{10}\right)\right](\mathrm{M}=\mathrm{Rh}, \mathrm{Ir} ; \mathrm{X}=\mathrm{Cl}, \mathrm{Br})$, as well as $\left[\left\{\mathrm{Ru}\left(\mathrm{TeI}_{4}\right)\left(\mathrm{TeI}_{2}\right)\right\}_{2}\left(\mathrm{Te}_{10}\right)\right]$, which all contain a neutral tellurium cage molecule $\mathrm{Te}_{10}[128,129]$ The same methodology involving tellurium, suitable metals, and tellurium tetrahalogenides yields $\left[\mathrm{Ru}\left(\mathrm{Te}_{9}\right)\right]\left[\mathrm{InCl}_{4}\right]_{2}$ and $\left[\mathrm{Ru}\left(\mathrm{Te}_{8}\right)\right] \mathrm{Cl}_{2}[130],\left[\mathrm{M}\left(\mathrm{Te}_{6}\right)\right] \mathrm{X}_{3}(\mathrm{M}=\mathrm{Rh}, \mathrm{Ir} ; \mathrm{X}=\mathrm{Cl}, \mathrm{Br}, \mathrm{I})$ and $\left[\mathrm{Ru}_{2}\left(\mathrm{Te}_{6}\right)\left(\mathrm{TeBr}_{3}\right)_{4}\left(\mathrm{TeBr}_{2}\right)_{2}\right]$ [131], all of which are one-dimensional coordination polymers containing an uncharged homonuclear tellurium ring.

The hydrothermal reaction of tellurium or selenium with silver and hydrogen iodide at $220{ }^{\circ} \mathrm{C}$ afforded $\left[(\mathrm{AgI})_{2}\left(\mathrm{Te}_{6}\right)\right]$ or the isomorphous selenium analogue $\left[(\mathrm{AgI})_{2}\left(\mathrm{Se}_{6}\right)\right][132]$.

\section{Summary}

Progress in the synthetic chemistry of selenium and tellurium is largely due to the development of a variety of reagents that can be applied both in inorganic and organic chemistry, as well as in materials science. Many of these useful reagents are available commercially, for instance elemental selenium and tellurium, selenium and tellurium dioxide, selenium and tellurium tetrahalogenides, some 
inorganic and organic selenides and tellurides, as well as diselenides and ditellurides. They can be used to synthesize more complex species, which can themselves act as precursors for further applications.

This chapter is an overview of the different reactions involving elemental selenium and tellurium. The synthetic details and reactions of their derivatives will be discussed in greater detail in Chapters 2-11. The first step in synthetic strategies often involves the reduction of the elements to chalcogenide or polychalcogenide ions, since they are stronger nucleophiles than the elements themselves. The most convenient reducing agents are alkali metals in liquid ammonia, sodium tetrahydridoborate, and lithium triethylhydridoaluminate ("superhydride"). Alkali metal and alkaline earth metal chalcogenides can also be prepared by direct mixing of the elements at high temperatures, by the reaction of chalcogen elements and alkali metal carbonates in solution, by solvothermal reactions, or by oxidation-reduction reactions involving Lewis acids.

Unlike commercially available $\mathrm{SeX}_{4}$ and $\mathrm{TeX}_{4}(\mathrm{X}=\mathrm{Cl}, \mathrm{Br}, \mathrm{I})$, the less-stable reagents, such as $\mathrm{SeCl}_{2}$ or $\mathrm{SeBr}_{2}$ need to be prepared and used in situ. This can conveniently be accomplished by the treatment of elemental selenium with sulfuryl chloride or bromide in THF. Both dihalides are stabilized in coordinating solvents. Tellurium dihalogenides cannot be prepared by the same route. Elemental selenium and tellurium also react with the Grignard reagents or organyllithium compounds affording organyl chalcogenolates that can easily be oxidized into organyl dichalcogenides. They play a role among the key reagents in organic and organometallic syntheses.

There are several methods to oxidize elemental selenium and tellurium to homo- and heteropolychalcogen cations. Their most significant feature is that they have been a source of new 
understanding of chemical bonding in main group compounds and have provided information of the relationships between the electronic structures and molecular structures.

\section{References}

[1] Krossing I, in Handbook of Chalcogen Chemistry: New Perspectives in Sulfur, Selenium and Tellurium, ed. F. A. Devillanova and W-W. du Mont, RSC Publishing, 2nd edn., Vol. 1, 2013, ch. 7.1, pp. 349-381.

[2] Petragnani N, Stefani H. Advances in organic tellurium chemistry. Tetrahedron 2005, 61, 1613-79.

[3] Chivers T, Laitinen RS. Tellurium: a maverick among the chalcogens. Chem Soc Rev 2015, 44, 1725-1739.

[4] Akhoon SA, Naqvi T, Nisar S, Rizvi MA. Synthetic organo-selenium compounds in medicinal domain: A Review. Asian J Chem 2015, 27, 2745-52.

[5] Potapov VA, Musalov MV, Musalova MV, Amosova SV. Recent advances in organochalcogen synthesis based on reactions of chalcogen halides with alkynes and alkenes. Curr Org Chem 2016, 20, 136-145.

[6] Chivers, T, Laitinen RS. Insights into the formation of inorganic heterocycles via cyclocondensation of primary amines with group 15 and 16 halides. Dalton Trans. 2017, 46, $1357-1367$

[7] Back TG. Ed. Organoselenium chemistry - A practical approach. Oxford University Press, Oxford, UK, 1999.

[8] Wirth T. Ed. Organoselenium Chemistry - Modern Developments in Organic Synthesis. Topics in Current Chemistry Vol. 208. Springer, Berlin, Germany, 2000. 
[9] Chivers, T. A Guide to Chalcogen-Nitrogen Chemistry, World Scientific Publishing, New Jersey 2005.

[10] Devillanova, FA. Ed. Handbook of Chalcogen Chemistry: New Perspectives in Sulfur, Selenium and Tellurium. RSC Publishing, Cambridge UK, 2007.

[11] Woollins JD, Laitinen RS. Eds. Selenium and tellurium chemistry; from small molecules to biomolecules and materials. Springer New York USA, 2011,

[12] Wirth T Ed. Organoselenium Chemistry, Wiley-VCH GmbH \& Co. KGaA, Weinheim Germany, 2012.

[13] Patai S, Rappoport Z. Eds. The chemistry of organic selenium and tellurium compounds. Vol. 3, Part 2, John Wiley \& Sons Ltd, Chichester UK 2012.

[14] Devillanova FA, du Mont W-W. Eds. Handbook of Chalcogen Chemistry, New Perspectives in Sulfur, Selenium and Tellurium. RSC Publishing, $2^{\text {nd }}$ Edn, Cambridge UK 2013.

[15] Jain VK, Priyadarsini KI. Eds. Organoselenium compounds in biology and medicine. RSC Publishing, Cambridge UK 2018.

[16] Poeppelmeier, K, Reedijk, J. Eds. Comprehensive Inorganic Chemistry II, $2^{\text {nd }}$ Ed., Volume 1, Elsevier: Amsterdam 2013.

[17] Kanatzidis MG, Huang SP. Coordination chemistry of heavy polychalcogen ligands. Coord Chem Rev 1994, 130, 509-621.

[18] Kanatzidis MG, Das BK. Superheated solvent media for organometallic (poly)chalcogenide cluster synthesis. Comm Inorg Chem 1999, 21, 29-51.

[19] Bergstrom FW. The polysulfides and polyselenides of lithium, sodium and potassium. J Am Chem Soc. 1926, 48,146-151.

[20] Klemm W, Sodomann H, Langmesser, P. Beiträge Zur Kenntnis der Alkalimetallchalkogenide. Z Anorg Allg Chem. 1939, 241, 281-304. 
[21] Brandsma L, Wijers H. A simple laboratory scale preparation method for dialkyl sulfides, selenides, tellurides, thiols, and selenols. Red Trav Chim Pays-Bas 1963, 82, 68-74.

[22] Müller V, Frenzen G, Dehnicke K. Synthese, FIR-Spektren und Kristallstrukturen der Pentaselenide. Z Naturforsch. 1992, 47b, 205-210.

[23] Björgvinsson M, Schrobilgen GJ. Homo- and heteropolychalcogenide anions $\mathrm{Ch}^{2-}, \mathrm{HCh}^{-}, \mathrm{Ch}_{2}^{2-}$, $\mathrm{Ch}_{3}{ }^{2-}$, and $\mathrm{Ch}_{4}{ }^{2-}\left(\mathrm{Ch}=\mathrm{Se}\right.$ and/or Te): Solution ${ }^{1} \mathrm{H},{ }^{77} \mathrm{Se},{ }^{123} \mathrm{Te}$, and ${ }^{125} \mathrm{Te}$ NMR study. Inorg Chem. 1991, 30, 2540-2547.

[24] Colombara D, Goncalves A-M, Etcheberry A. Synthesis of $\mathrm{K}_{2}$ Se solar cell dopant in liquid $\mathrm{NH}_{3}$ by solvated electron transfer to elemental selenium. Electrochem Commun 2018, 93, 44-48.

[25] Thiele G, Vondung L, Donsbach C, Pulz S,Dehnen S. Organic cation and complex cationstabilized (poly-)selenides, [cation $]_{x}\left(\mathrm{Se}_{y}\right)_{z}$ : Diversity in structures and properties. Z Anorg Allg Chem 2014, 640, 2684-2700.

[26] Kysliak O, Beck J. Zn, Mn, and Fe hexammine and hexakis(methylamine) polychalcogenides - Ionic compounds by solvothermal synthesis. Inorg Chem Commun 2013, 38, 146-151.

[27] Sandman DJ, Stark JC, Acampßora LA, Gagne P. A Direct Broadly Applicable Approach to the Synthesis of Aromatic Molecular and Supramolecular Selenium and Tellurium Compounds. Organometallics 1983, 2, 549-551.

[28] Thompson DP, Boudjouk P. A Convenient Synthesis of Alkali Metal Selenides and Diselenides in Tetrahydrofuran and the Reactivity Differences Exhibited by These Salts toward Organic Bromides. Effect of Ultrasound. J Org Chem 1988, 53, 2109-2112.

[29] Gautheron B, Degrand C. Electroreduction of selenium at a mercury pool cathode in aprotic media. Application to the electrosynthesis of dibenzyl selenide and diselenide. J Electroanal Chem 1984, 163, 415-418.

[30] Gautheron B, Tainturier G, Degrand C. Ultrasound-Induced Electrochemical Synthesis of the Anions $\mathrm{Se}_{2}{ }^{2-}, \mathrm{Se}^{2-}, \mathrm{Te}_{2}{ }^{2-}$, and $\mathrm{Te}^{2-} . \mathrm{J}$ Am Chem Soc 1985, 107, 5579-5581. 
[31] Ishihara H, Koketsu M, Fukuta Y, Nada F. Reaction of lithium aluminum hydride with elemental selenium: Its application as a selenating reagent into organic molecules. J Am Chem Soc 2001, 123, 8408-8409.

[32] Klayman DL, Griffin TS. Reaction of selenium with sodium borohydride in protic solvents. A facile method for the introduction of selenium into organic molecules. J Am Chem Soc 1973, 95, 197-199, and references cited therein.

[33] Gladysz, JA, Hornby JL, Garbe, JE. Convenient one-flask synthesis of dialkyl selenides and diselenides via lithium triethylborohydride reduction of $\mathrm{Se}_{\mathrm{x}}$. J Org Chem 1978, 43, 1204 1208 .

[34] Cusick J, Dance I. The characterization of [HSe $]^{-}$and $\left[\mathrm{Se}_{x}\right]^{2-}$ ions by ${ }^{77} \mathrm{Se} \mathrm{NMR}$. Polyhedron $1991,10,2629-2640$.

[35] Marques de Oliveira AR, Piovan L, Simonelli F, Barison A, de Fatima de Santos M, Marcondes de Mello MB. A ${ }^{77}$ Se NMR study of elemental selenium reduction using $\mathrm{NaBH}_{4}$. J Organomet Chem 2016, 806, 54-59.

[36] Raymond CC, Dick DL, Dorhout PK. Speciation of main-group metal ions by electrospray mass spectrometry. 1. Investigation of aqueous polyselenide species and effects of cations and pH. Inorg Chem 1997, 36, 2678-2681.

[37] Zhang J, Zhang S, Zhang H, Zhang Y, Zheng Z, Xiang Y. Activated selenium for promoted formation of metal selenide nanocrystals in solvothermal synthesis. Mater Lett 2014, 122, 306-308.

[38] Fenske D, Adel J Dehnicke K. The crystal structure of bis $\left(\eta^{5}\right.$ cyclopentadienyl)titana(TiIV)pentaselenacyclohexane, $\mathrm{Cp}_{5}$ TiSe $_{5}$. Z Naturforsch 1987, 42b, 931-933 
[39] Albrecht N, Weiss J. Bis( $\eta^{5}$-cyclopentadienyl)(pentaselenido)metal complexes, $\mathrm{Cp}_{2} \mathrm{MSe}_{5}$, of titanium, zirconium, and hafnium and $\left(\mu_{2}-\mathrm{O}\right)\left(\mu_{2}-\mathrm{Se}_{4}\right)\left(\mathrm{Cp}_{2} \mathrm{Hf}\right)_{2}$, a binuclear compound with tetraselenide and oxygen bridges. J Organomet Chem 1988, 355, 89-98.

[40] Pekonen P, Hiltunen Y, Laitinen RS. The selenium-selenium coupling in bis(cyclopentadienyl)titanium pentaselenide $\left[\mathrm{Ti}\left(\mathrm{C}_{5} \mathrm{H}_{5}\right)_{2} \mathrm{Se}_{5}\right]$. Acta Chem Scand 1989, 43, 914-916.

[41] Giolando DM, Papavassiliou M, Pickardt J, Rauchfuss TB, Steudel R. Synthesis and structure of 1,4-[(RCp $\left.)_{2} \mathrm{Ti}\right]_{2} \mathrm{Se}_{4}$ and its application to the chalcogenospecific synthesis of 1,2,5,6-Se $4 \mathrm{~S}_{4}$. Inorg Chem 1988, 27, 2596-2600.

[42] Steudel R, Papavassiliou M, Strauss E-M, Laitinen R. Sulfur compounds 95. A series of selenium rich chalcogen ring $\left(\mathrm{Se}_{5} \mathrm{~S}, \mathrm{Se}_{5} \mathrm{~S}_{2}, \mathrm{Se}_{7}\right)$ from titanocene pentaselenide. Angew Chem Int Ed Engl 1986, 25, 99-101.

[43] Pekonen P, Hiltunen Y, Laitinen RS, Pakkanen TA. Chalcogen Ring Interconversion Pathways. ${ }^{77} \mathrm{Se}$ NMR spectroscopic study of the decomposition of $1,2,3,4,5-\mathrm{Se}_{5} \mathrm{~S}_{2}$ to $1,2,3,4,5,6-\mathrm{Se}_{6} \mathrm{~S}_{2}$ and 1,2,3,4-Se $\mathrm{S}_{2}$. Inorg Chem 1991, 30, 3679-3682.

[44] Steudel R. The synthesis of sulfur- and selenium-containing organic and inorganic rings from titanocene precursors. Studies Inorg Chem 1992, 14, 233-253.

[45] Pekonen P, Suontamo R., Laitinen RS. Homo- and heteroatomic chalcogen rings. Coord Chem Rev 1994, 130, 1-62, and references cited therein.

[46] Steudel R, Eckert B. Solid sulfur allotropes. Top Curr Chem 2003, 230, 1-79.

[47] Steudel R, Jensen D, Papavassiliou M. Sulfur and selenium compounds 123. Dinuclear titanocene chalcogenides as sulfur and selenium transfer reagents in ring synthesis. Phosphorus Sulfur Silicon Relat Chem 1989, 41, 349-353 
[48] Papavassiliou M, Pickardt J, Steudel R. Sulfur compounds 153. Synthesis, structure and reactions of $\mathrm{Cp}_{2}{ }_{2} \mathrm{TiSe}_{3} \mathrm{~S}_{2}$ and $\mathrm{Cp}_{2}{ }_{2} \mathrm{TiSe}_{4} \mathrm{~S}\left(\mathrm{Cp}^{\prime}=\eta^{5}-\mathrm{C}_{5} \mathrm{H}_{4} \mathrm{CH}_{3}\right)$. Phosphorus Sulfur Silicon Relat Elem 1992, 65, 161-164.

[49] Pekonen P, Hiltunen Y, Laitinen RS, Valkonen J. ${ }^{77}$ Se NMR spectroscopic and X-ray crystallographic characterization of bis(cyclopentadienyl)titanium selenide sulfide mixtures, $\left[\mathrm{Ti}\left(\mathrm{C}_{5} \mathrm{H}_{5}\right)_{2} \mathrm{Se}_{x} \mathrm{~S}_{5-x}\right]$. Inorg. Chem. 1991, 30, 1874-1878.

[50] Silva L, Affeldt RF, Lüdtke DS. Synthesis of glycosyl amides using selenocarboxylates as traceless reagents for amide bond formation. J Org Chem 2016, 81, 5464-5473.

[51] Potapov VA, Amosova SV. New methods for preparation of organoselenium and organotellurium compounds from elemental chalcogens. Russ J Org Chem 2003, 39, 1373 1380, and references cited therein.

[52] Giribabu K, Suresh R, Manigandan R, Thirumal E, Stephen A, Narayanan V. Aqueous based synthesis of $\mathrm{Cu}_{5} \mathrm{Se}_{4}$ nanosheets. J Mater Sci 2013, 24, 1888-1894.

[53] Khanna PK, Subbarao VVVS, Wagh M, Jadhav P, Patil KR. Synthesis of fine PbE (E=S, Se) powder from direct in situ reduction of sulphur or selenium. Mater Chem Phys 2005, 93, 9194.

[54] McCarthy CL, Downes CA, Brutchey RL. Room temperature dissolution of bulk elemental $\mathrm{Ni}$ and Se for solution deposition of $\mathrm{NiSe}_{2}$ HER electrocatalyst. Inorg Chem 2017, 56, 10143 10146.

[55] Bastola E, Bhandari KP, Matthews AJ, Shrestha N, Ellingson RJ. Elemental anion thermal injection synthesis of nanocrystalline marcasite iron dichalcogenide $\mathrm{FeSe}_{2}$ and $\mathrm{FeTe}_{2}$. RSC Adv 2016, 6, 69708-69714.

[56] Tan L, Fu J, Liu S. Growth of photoluminescent $\mathrm{Ag}_{2} \mathrm{Se}$ nanowires from simple precursor solution. CrystEngComm 2014, 16, 10534-10538. 
[57] Lamoureux $\mathrm{M}$, Milne J. The disproportionation of diselenium dichloride $\mathrm{Se}_{2} \mathrm{Cl}_{2}$ and diselenium dibromide $\mathrm{Se}_{2} \mathrm{Br}_{2}$. Can J Chem 1989, 67, 1936-1941.

[58] Milne J, Williams AJ. Exchange process in diselenium and selenium-sulfur dihalides, $\mathrm{Se}_{2} \mathrm{X}_{2}$ and $\mathrm{SeSX}_{2}(\mathrm{X}=\mathrm{Br}, \mathrm{Cl})$. Inorg Chem 1992, 31, 4534-4538.

[59] Maaninen A, Chivers T, Parvez M, Pietikäinen J, Laitinen RS. Syntheses of THF solutions of $\mathrm{SeX}_{2}(\mathrm{X}=\mathrm{Cl}, \mathrm{Br})$ and a new route to selenium sulfides $\mathrm{Se}_{\mathrm{n}} \mathrm{S}_{8-\mathrm{n}}(\mathrm{n}=1-5)$; crystal structures of $\mathrm{SeCl}_{2}$ (tht) $)_{2}$ and $\mathrm{SeCl}_{2} \bullet$ tmtu (tmtu = tetramethylthiourea). Inorg. Chem. 1999, 38, 4093-4097.

[60] Laitinen RS, Pakkanen TA. ${ }^{77}$ Se NMR spectroscopic characterization of selenium sulfide ring molecules $\mathrm{Se}_{n} \mathrm{~S}_{8-n}$. Inorg Chem 1987, 26, 2598-2603.

[61] Laitinen RS, Oilunkaniemi R. Catenated Compounds: Group 16 (Se, Te)., In Poeppelmeier, K, Reedijk J. Eds. Comprehensive Inorganic Chemistry II, $2^{\text {nd }}$ Ed., Elsevier, Amsterdam 2013, pp 197-231.

[62] Ahmed E, Ruck M. Homo- and heteroatomic polycations of groups 15 and 16. Recent advances in synthesis and isolation using room temperature ionic liquids. Coord Chem Rev 2011, 255, 2892-2903, and references cited therein.

[63] Beck J, Rings, cages and chains - the rich structural chemistry of the polycations of the chalcogens. Coord Chem Rev 1997, 163, 55-70, and references cited therein.

[64] Artem'ev AV, Chernysheva NA, Yas'ko SV, et al. Straightforward solvent-free synthesis of tertiary phosphine chalcogenides from secondary phosphines, electron-rich alkenes, and elemental sulfur or selenium. Heteroatom Chem 2016, 27, 48-53.

[65] Artem'ev AV, Chenysheva NA, Gusarova NK et al. Reaction of vinyl selenides with secondary phosphines and elemental selenium: One-pot selective synthesis of a new family of diselenophosphinic Se-esters. Heteroatom Chem 2014, 25, 135-139.

[66] Kuwajima I, Shimizu M, Urabe H. Oxidation of alcohols with tert-butyl hydroperoxide and diaryl diselenide. J Org Chem 1982, 47, 837-842, and references cited therein. 
[67] Jen K-Y, Cava MP. Improved synthesis of aromatic diselenides. J Org chem 1983, 48, 14491451 , and references cited therein.

[68] Oilunkaniemi R, Laitinen RS, Ahlgrén M. The solid state conformation of diaryl ditellurides and diselenides: The crystal and molecular structures of $\left(\mathrm{C}_{4} \mathrm{H}_{3} \mathrm{E}\right)_{2} \mathrm{E}_{2}{ }_{2}\left(\mathrm{E}=\mathrm{O}, \mathrm{S} ; \mathrm{E}^{\prime}=\mathrm{Te}, \mathrm{Se}\right)$. Z Naturforsch 2000, 55b, 361-368.

[69] Ilie A, Crespo O, Gimeno MC, et al. (N,Se) and (Se,N,Se) ligands based on carborane and pyridine fragments - Reactivity of 2,6-[(1'-Me-2',3'-closo- $\left.\left.\mathrm{C}_{2} \mathrm{~B}_{10} \mathrm{H}_{10}\right) \mathrm{SeCH}_{2}\right]_{2} \mathrm{C}_{5} \mathrm{H}_{3} \mathrm{~N}$ towards copper and silver. Eur J Inorg Chem 2017, 2643-2652.

[70] Gujral G, Gulati SD, Bhasin KK, Potapov VA, Amosova SV. Synthesis and characterization of unsymmetric 4-picolyl selenides. Phosphorus Sulfur Silicon 2016, 191, 55-58.

[71] Lu F. Elemental sulfur as soft oxidant for facile one-pot preparation of air-sensitive organometallic di[5]trovacenyldichalcogenides. Inorg Chem Commun 2013, 37, 148-150.

[72] Karjalainen MM, Sanchez-Perez C, Rautiainen JM, Oilunkaniemi R, Laitinen RS. Chalcogenchalcogen secondary bonding interactions in trichalcogenaferrocenophanes. CrystEngComm 2016, 18, 4538-4545, and references cited therein.

[73] Chan Y-C, Li Y, Gangly R, So C-W. Acyclic amido-containing silanechalcogenones. Eur J Inorg Chem 2015, 3821-3824.

[74] Matsumoto T, Tokitoh N, Okazaki R. The first kinetically stabilized germanethiones and germaneselenones: Syntheses, structures, and reactivities. J Am Chem Soc 1999, 121, 88118824.

[75] Karwasara S, Yadav D, Jha CK, Rajaraman G, Nagendran S. Single-step conversion of silathiogermylene to germaacid anhydrides; unusual reactivity. Chem Commun 2015, 51, 43104313.

[76] Karwasara S, Siwatch RK, Jha CK, Nagendran S. Aminotroponiminatosilathio- and siloxygermylenes: Reactivity comparison. Organometallics 2015, 34, 3246-3254. 
[77] Ito M, Tokitoh N, Kawashima T, Okazaki R. Formation of borylene by photolysis of an overcrowded bis(methylseleno)borane. Tetrahedron Lett 1999, 40, 5557-5560.

[78] Braunschweig H, Dellermann T, Ewing WC, Kramer T, Schneider C, Ullrich S. Reductive insertion of elemental chalcogens into boron-boron multiple bonds. Angew Chem Int Ed $2015,54,10271-10275$.

[79] Braunschweig $\mathrm{H}$, Constantinidis P, Dellermann $\mathrm{T}$, et al. Highly strained heterocycles constructed from boron-boron multiple bonds and heavy chalcogens. Angew Chem Int Ed 2016, 55, 5606-5609.

[80] Kanatzidis MG. Molten alkali-metal polychalcogenides as reagents and solvents for the synthesis of new chalcogenide materials. Chem Mater 1990, 2, 353-363.

[81] (a) Kanatzidis MG, Sutorik AC. The application of polychalcogenide salts to the exploratory synthesis of solid state multinary chalcogenides at intermediate temperatures. Prog. Inorg. Chem. 43 (1995) 151-265; (b) Sheldrick WS, Wachhold M. Solventothermal synthesis of solid-state chalcogenidometalates. Angew Chem. Int. Ed. Engl. 36 (1997) 206-224.

[82] Sheldrick WS. Polychalcogenides. In Devillanova FA, du Mont W-W. Eds. Handbook of chalcogen chemistry - New perspectives in sulfur, selenium and tellurium. RSC Publishing. Cambridge $2^{\text {nd }}$ edn, Vol 1, 2013, 514-545.

[83] Zhou J. Synthesis of heterometallic chalcogenides containing lanthanide and group 13-15 metal elements. Coord Chem Rev 2016, 315, 112-134.

[84] Housecroft CE, Sharpe AG. Inorganic Chemistry. $5^{\text {th }}$ ed, Pearson Education Ltd., Harlow, UK, 2018.

[85] Hayashi S, Nakanishi W. Hypervalent compounds. in Devillanova FA, du Mont W-W. Eds. Handbook of Chalcogen Chemistry: New Perspectives in Sulfur, Selenium and Tellurium. $2^{\text {nd }}$, Ed, Vol.2, RSC Publishing, Cambridge 2013, 335-372. 
[86] Cozzolino, AF, Elder PJW, Vargas-Baca I. A survey of tellurium-centered secondary-bonding supramolecular synthons. Coord Chem Rev, 2011, 255, 1426-1438.

[87] Basmadijan GP, Parker GR, Magarian RA, Ice RD, Mills SL, Kirschner AS. Synthesis of tellurium-123m-labeled nucleophiles: potential use in the synthesis of new tellurium-123mlabeled radiopharmaceuticals. Int J Appl Rad Isot 1980, 31, 517-520.

[88] Ramasamy K, Nejo AO, Ziqubu N, et al. A new route to lead chalcogenide nanocrystals. Eur J Inorg Chem 2011, 5196-5201.

[89] Yao D, Liu Y, Zhao W, et al. A totally phosphine-free synthesis of metal telluride nanocrystals by employing alkylamides to replace alkylphosphines for preparing highly reactive tellurium precursors. Nanoscale 2013, 5, 9593-9597.

[90] Kumar J, Mahesh HM. Concentration-dependent optical properties of TGA stabilized CdTe quantum dots synthesized via the single injection hydrothermal method in the ambient environment. Superlatt. Microstruct. 2017, 104, 118-127.

[91] Kumar A, Dittmer, DC. A catalytic process for the transposition of allylic hydroxyl groups and carbon-carbon double bonds. Tetrahedron Lett 1994, 35, 5583-5586.

[92] Detty MR, Seidler MD. Bis(trialkylsilyl) chalcogenides. 1. Preparation and reduction of group 6A oxides. J Org Chem. 1982, 47, 1354-1356.

[93] Taavitsainen J, Laitinen RS. Tellurium-containing chalcogen rings. Main Group Chem 1999, 3, 59-67.

[94] Finger LH, Sundermeyer J. Halide-free synthesis of hydrochalcogenide ionic liquids of the type [cation][HE] (E = S, Se, Te). Chem Eur J 2016, 22, 4218-4230.

[95] Björgvinsson M, Sawyer JF, Schrobilgen GJ. crystal structures of potassium cryptated salts of the $\mathrm{TeSe}_{2}{ }^{2-}$, pyramidal $\mathrm{TeSe}_{3}{ }^{2-}$, and mixed compounds containing pyramidal $\mathrm{TeSe}_{3}{ }^{2-}$ and chain $\mathrm{Te}_{x} \mathrm{Se}_{4-x}{ }^{2-}$ 
[96] Sekar P, Ibers JA. Syntheses and characterization of some mixed Te/Se polychalcogenide anions $\left[\mathrm{Te}_{m} \mathrm{Se}_{n}\right]^{2-}$. Inorg Chem 2004, 43, 5436-5441.

[97] Fenske D, Grissinger A. Zur Reaktion von $\left[\mathrm{Cp}_{2}{ }_{2} \mathrm{TiCl}_{2}\right]$ und $\left[\mathrm{Cp}^{\prime} \mathrm{TiCl}_{3}\right]$ mit $\mathrm{E}\left(\mathrm{SiMe}_{3}\right)_{2}(\mathrm{E}=$ Se, Te; $\left.\mathrm{Cp}^{\prime}=\mathrm{C}_{5} \mathrm{H}_{4} \mathrm{CH}_{3}\right)$. Die Kristalstrukturen von [Cp' $\left.{ }_{4} \mathrm{Ti}_{2} \mathrm{Te}_{4}\right], \quad\left[\mathrm{Cp}_{5}{ }_{5} \mathrm{Ti}_{5} \mathrm{Se}_{6}\right]$ und [Cp' $\left.{ }_{5} \mathrm{Ti}_{5} \mathrm{Te}_{6}\right]$. Z Naturforsch 1990, 34b, 1309-1313.

[98] Haas A, Kutsch HJ. Preparation and characterization of hexakis(trifluoromethyl)digermachalcogenides. Chem Ber 1988, 121, 803-804.

[99] Sewing D, du Mont W-W, Pohl S, Saak W, Lenoir D. Diacyltelluride: Synthese durch Reaktionen von Acylchloriden mit Bis(trialkylsilyl)telluriden; Strukturbestimmungen an Di(1-adamantoyl)tellurid und Adamantancarbonsäureanhydrid. Z Anorg Allg Chem 1998, 1363-1368, and references cited therein.

[100] Borecki A, Corrigan JF. New copper and silver trimethylsilylchalcogenolates. Inorg Chem 2007, 46, 2478-2484, and references cited therein.

[101] Merzweiler K, Kraus H. New organometallic tin-tellurium compounds. Syntheses and crystal structures of $\left[\left\{\mathrm{Cp}(\mathrm{CO})_{2} \mathrm{Fe}\right\}_{4} \mathrm{Sn}_{2} \mathrm{Te}_{2}\right]$ and $\left[\left\{\mathrm{Cp}(\mathrm{CO})_{3} \mathrm{Mo}\right\}_{4} \mathrm{Sn}_{4} \mathrm{Te}_{6}\right]$. Z Naturforsch 1994, 49b, 621-626.

[102] Pore V, Hatanpää T, Ritala M, Leskelä M. Atomic layer deposition of metal tellurides and selenides using alkylsilyl compounds of tellurium and selenium. J Am Chem Soc 2009, 131, $3478-3480$.

[103] Pietikäinen J, Laitinen RS. Novel tellurium halides $\mathrm{Te}_{2} \mathrm{Cl}_{2}$ and $\mathrm{Te}_{2} \mathrm{Br}_{2}$. Chem Commun 1998, $2381-2382$.

[104] Panda A, Developments in tellurium containing macrocycles Coord Chem Rev 2009, 253, 1946-1965. 
[105] Chivers T, Laitinen RS, Schmidt KJ, Taavitsainen J. NMR spectroscopic evidence for the existence of tellurium-containing chalcogen rings and polymers in sulfur-tellurium and sulfurselenium-tellurium melts. Inorg Chem 1993, 32, 337-340.

[106] Zingaro RA. Tributylphosphine telluride. J Organomet Chem 1963, 1, 200.

[107] Zingaro RA, Steeves BH, Irgolick K. Phosphine tellurides. J Organomet Chem 1965, 4, 320323.

[108] Nordheider A, Woollins JD, Chivers T. Organophosphorus-tellurium chemistry: from fundamentals to applications. Chem Rev 2015, 115, 10378-10406.

[109] Brennan JG, Siegrist T, Stuczynski SM, Steigerwald ML. Cluster intermediates in an organometallic synthesis of palladium telluride PdTe. J Am Chem Soc 1990, 112, 9233-9236.

[110] Mastai Y, Hodes G. Size quantization in electrodeposited CdTe nanocrystalline films. J Phys Chem B 1997, 101, 2685-2690.

[111] Daniliuc C, Druckenbrodt C, Hrib CG, et al. The first trialkylphosphane telluride complexes of $\operatorname{Ag}(\mathrm{I})$ : molecular, ionic and supramolecular structural alternatives. Chem Commun 2007, 2060-2062.

[112] Mallek R, Sanhoury MAK, Ben Dhia MT, Khaddar MR. Cadmium(II) complexes with phosphine tellurides: synthesis and multinuclear $\left({ }^{31} \mathrm{P},{ }^{125} \mathrm{Te}\right.$, and $\left.{ }^{113} \mathrm{Cd}\right) \mathrm{NMR}$ characterization in solution. J Coord Chem 2014, 67, 1541-1549.

[113] Mallek R, Sanhoury MAK, Bahri L, Khaddar MR, Ben Dhia MT. Synthesis, characterization, and solution behavior of mercury(II) chloride complexes with phosphine tellurides. J Coord Chem 2016, 69, 726-734.

[114] Engman L, Cava MP. Organotellurium compounds 6. Synthesis and reactions of some heterocyclic lithium tellurolates. Organometallics 1982, 1, 470-473. 
[115] Bhasin KK, Arora V, Klapötke TM, Crawford M-J. One-pot synthesis of pyridyltellurium derivatives from a reaction with isopropylmagnesium chloride and X-ray crystal structures of various pyridyl ditellurides. Eur J Inorg Chem 2004, 4781-4788.

[116] Frogley BJ, Hill AF, Manzano RA, Sharma M. Bis(alkylidynyl)tellurides and ditellurides. Chem Commun 2018, 54, 1702-1705.

[117] Briand GG, Chivers T, Parvez M, Schatte G. Experimental and theoretical investigations of lithium and magnesium derivatives of bis(tert-butylamido)cyclodiphosph(III/V)- and (V/V)azane mono and ditellurides. Inorg Chem 2003, 42, 525-531.

[118] Song L-C, Yan C-G, Hu, Q-M, Huang X-Y. Formation of novel tellurium-containing anions $\left[(\mu-\mathrm{RTe})(\mu-\mathrm{CO}) \mathrm{Fe}_{2}(\mathrm{CO})_{6}^{-}\right]$and synthesis of $\mathrm{Fe} / \mathrm{Te}$ clusters $(\mu-\mathrm{RTe})(\mu-\sigma, \pi-$ $\left.\mathrm{PhC}=\mathrm{CH}_{2}\right) \mathrm{Fe}_{2}(\mathrm{CO})_{6}, \quad(\mu-\mathrm{RTe})_{2} \mathrm{Fe}_{2}(\mathrm{CO})_{6}, \quad$ and $\quad\left[(\mu-\mathrm{RTe}) \mathrm{Fe}_{2}(\mathrm{CO})_{6}\right]_{2}(\mu-\mathrm{Te}-\mathrm{Te}-\mu)$. Organometallics 1997, 16, 3769-3774.

[119] Iwamoto T, Sato K, Ishida S, Kabuto C, Kira M. Synthesis, properties and reactions of a series of stable dialkyl-substituted silicon-chalcogen doubly bonded compounds. J Am Chem Soc 2006, 128, 16914-16920.

[120] Tokitoh N, Matsumoto T, Okazaki R. First stable germanetellones: Syntheses and crystal structures of the heaviest germanium-chalcogen double-bond compound. J Am Chem Soc $1997,119,2337-2338$.

[121] Liu S, Légaré M-A, Auerhammer D, Hofmann A, Braunschweig H. The first boron-tellurium double bond: Direct insertion of heavy chalcogens into a $\mathrm{Mn}=\mathrm{B}$ double bond. Angew $\mathrm{Chem}$ Int Ed 2017, 56, 15760-15763.

[122] Cowley AH, Jones PR, Harris PR, Atwood DA, Contreras L, Burek CJ. Tetrameric gallium and aluminium chalcogenides $\left[\mathrm{Me}_{3} \mathrm{CMX}\right]_{4}(\mathrm{M}=\mathrm{Al}, \mathrm{Ga} ; \mathrm{X}=\mathrm{S}, \mathrm{Se}, \mathrm{Te})$. A new class of heterocubanes. Angew Chem Int Ed Engl 1991, 30, 1143-1146. 
[123] Power MB, Ziller JW, Tyler AN, Barron AR. Interaction of tri-tert-butylgallium with elemental sulfur, selenium, and tellurium. Organometallics 1992, 11, 1055-1063.

[124] Power MB, Barron AR. Isolation of the first gallium hydrosulfido complex and its facile conversion to $\mathrm{Ga}_{4} \mathrm{~S}_{4}$ cubane: X-ray structure of $\left[\text { tert }-\mathrm{Bu}_{2} \mathrm{Ga}(\mu-\mathrm{SH})\right]_{2}$ and $[\text { tert-BuGaS }]_{4}$. $\mathrm{J}$ Chem Soc Chem Commun 1991, 1315-1317.

[125] Li GM, Zingaro RA. Reaction of diisobutylaluminium hydride with selenium and tellurium: new reagents for the synthesis of seleno- and telluro-amides. J Chem Soc, Perkin Trans I 1998,647-649.

[126] Fischer JM, Piers WE, MacGillivray LR, Zaworotko MJ. Permethyltitanocene tellurides and ditellurides. X-ray structures of $\left[\left(\mathrm{C}_{5} \mathrm{Me}_{5}\right)_{2} \mathrm{Ti}\right]_{2}(\mu-\mathrm{Te})$ and $\left(\mathrm{C}_{5} \mathrm{Me}_{5}\right)_{2} \mathrm{Ti}\left(\eta^{2}-\mathrm{Te}_{2}\right)$. Inorg Chem 1995, 34, 2499-2500.

[127] Fischer JM, Piers WE, Ziegler T, MacGillivray LR, Zaworotko MJ. Permethyltitanocene derivatives with naked chalcogen ligands: Synthesis of $\left[\left(\mathrm{Cp}^{*}{ }_{2} \mathrm{Ti}\right){ }_{2}(\mu-\mathrm{E})\right]$ and $\left.\mathrm{Cp}{ }_{2} \mathrm{Ti}\left(\eta^{2}-\mathrm{E}_{2}\right)\right]$ and the role of the terminal chalcogenides $\left[\mathrm{Cp}^{*}{ }_{2} \mathrm{Ti}(\mathrm{E})\right]$ in their interconversion $(\mathrm{E}=\mathrm{Se}, \mathrm{Te})$. Chem Eur J 1996, 2, 1221-1229.

[128] Günther A., Heise M, Wagner FR, Ruck M. An iridium-stabilized formally uncharged Te ${ }_{10}$ molecules with 3-center-4-electron bonding. Angew Chem Int Ed 2011, 50, 9987-9990.

[129] Günther A, Isaeva A, Ruck M. Stabilization of decatellurium molecules in isolated and concatenated clusters. Z Anorg Allg Chem 2013, 639, 254-260.

[130] Günther A, Isaeva A, Baranov AI, Ruck M. Neutral tellurium rings in the coordination polymers $\left[\mathrm{Ru}\left(\mathrm{Te}_{9}\right)\right]\left(\mathrm{InCl}_{4}\right)_{2},\left[\mathrm{Ru}\left(\mathrm{Te}_{8}\right)\right] \mathrm{Cl}_{2}$, and $\left[\mathrm{Rh}\left(\mathrm{Te}_{6}\right)\right] \mathrm{Cl}_{3}$. Chem Eur J 2011, 17, 63826388.

[131] Günther A, Ruck M. Hexatellurium rings in coordination polymers and molecular clusters: Synthesis and crystal structures of $\left[M\left(\mathrm{Te}_{6}\right)\right] X_{3}(M=\mathrm{Rh}, \mathrm{Ir} ; X=\mathrm{Cl}, \mathrm{Br}, \mathrm{I})$ and $\left[\mathrm{Ru}_{2}\left(\mathrm{Te}_{6}\right)\right]\left(\mathrm{TeBr}_{3}\right)_{4}\left(\left(\mathrm{TeBr}_{2}\right)_{2}\right.$. Z Anorg Allg Chem 2012, 638, 317-323. 
[132] Deiseroth H-J, Wagener M, Neumann E. $(\mathrm{AgI})_{2} \mathrm{Te}_{6}$ and $(\mathrm{AgI})_{2} \mathrm{Se}_{6}$ : New composite materials with cyclic $\mathrm{Te}_{6}$ and $\mathrm{Se}_{6}$ molecules stabilized in the "solid solvent" AgI. Eur J Inorg Chem 2004, 4755-4758. 